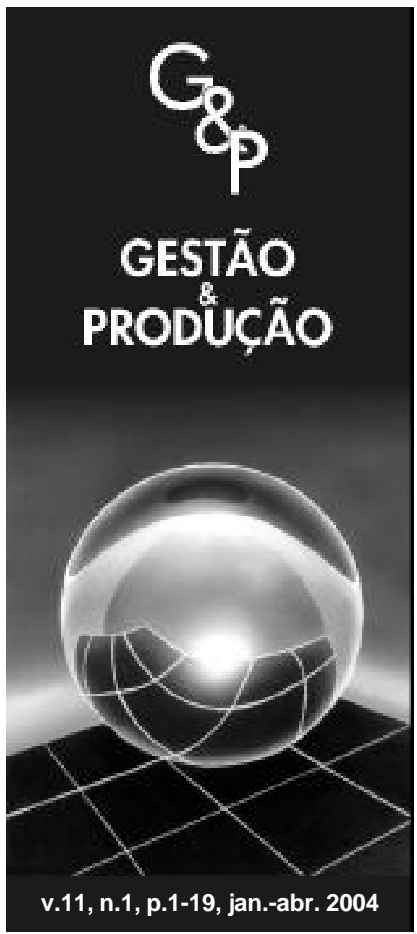

\title{
MANUFATURA ENXUTA: UMA REVISÃO QUE CLASSIFICA E ANALISA OS TRABALHOS APONTANDO PERSPECTIVAS DE PESQUISAS FUTURAS
}

\author{
Moacir Godinho Filho \\ Flavio César Faria Fernandes \\ Departamento de Engenharia de Produção, \\ Programa de Pós-Graduação, \\ Universidade Federal de São Carlos, \\ C.P. 676, CEP 13565-905, São Carlos, SP, \\ e-mails: moacir_godinho@uol.com.bredfcf@power.ufscar.br
}

\section{Resumo}

Este trabalho apresenta uma revisão bibliográfica (82 artigos) sobre a Manufatura Enxuta (ME), revisão esta não encontrada até agora na literatura de Gestão da Produção. A partir de tal revisão propôs-se um sistema de classificação para a ME baseada em 4 parâmetros: metodologia, abrangência, princípios e capacitadores, a qual serviu para classificar e estruturar os artigos da revisão. Uma vez classificada e estruturada, a revisão bibliográfica sobre ME serviu de base para uma ampla análise do tema. Essa análise se baseou em dois pontos fundamentais: i) um estudo quantitativo das metodologias, abrangências, princípios e capacitadores utilizados nos trabalhos e ii) um estudo qualitativo dos principais assuntos e objetivos alcançados por esses trabalhos. As principais contribuições deste trabalho são: servir de base para um maior conhecimento da literatura existente atualmente sobre ME e propor sugestões de pesquisas futuras na área.

Palavras-chave: Manufatura Enxuta, revisão.

\section{Introdução}

O presente trabalho trata do tema Manufatura Enxuta, também conhecido como Sistema Toyota de Produção (STP), o qual teve início na década de 1950, no Japão, mais especificamente na Toyota. De acordo com Womack et al. (1992), foram Eiiji Toyoda e Taiichi Ohno, da Toyota, que perceberam que a manufatura em massa não funcionaria no Japão e, então, adotaram uma nova abordagem para a produção, a qual objetivava a eliminação de desperdícios. Para conseguir esse objetivo, técnicas como produção em pequenos lotes, redução de set up, redução de estoques, alto foco na qualidade, dentre outras, eram utilizadas. Essa nova abordagem passou a ser conhecida como Sistema Toyota de Produção. Apesar do STP muitas vezes ser entendido como algo novo, na verdade, muitos de seus princípios são trabalhos de pioneiros como Deming, Taylor e Skinner (James-Moore \& Gibbons,
1997). O STP foi popularizado no ocidente por Womack et al. (1992). Esses autores denominam o STP de Manufatura Enxuta.

Atualmente coexistem várias definições para a Manufatura Enxuta (ME). Womack \& Jones (1998), por exemplo, definem ME como uma abordagem que busca uma forma melhor de organizar e gerenciar os relacionamentos de uma empresa com seus clientes, cadeia de fornecedores, desenvolvimento de produtos e operações de produção, segundo a qual é possível fazer cada vez mais com menos (menos equipamento, menos esforço humano, menos tempo, etc.). Segundo Shah \& Ward (2003), a abordagem da ME engloba ampla variedade de práticas gerenciais, incluindo just in time, sistemas de qualidade, manufatura celular, entre outros. Ainda de acordo com esse autor, o ponto fundamental da ME é que essas práticas devem trabalhar de maneira sinérgica para criar um sistema de alta qualidade que fabrica produtos no ritmo que o cliente deseja, sem desperdícios. 
A partir de características da ME citadas por diversos autores sobre o tema e no intuito de fornecer uma definição mais precisa para a Manufatura Enxuta, Godinho Filho (2004) apresenta a ME como um Paradigma Estratégico de Gestão da Manufatura (PEGEM), ou seja, define a Manufatura Enxuta como um modelo estratégico e integrado de gestão, direcionado a certas situações de mercado, que propõe auxiliar a empresa a alcançar determinados objetivos de desempenho (qualidade e produtividade); paradigmas esses compostos por uma série de princípios (idéias, fundamentos, regras que norteiam a empresa) e capacitadores (ferramentas, tecnologias e metodologias utilizadas).

Neste artigo apresentamos uma revisão da literatura sobre ME da maneira mais ampla possível, tentando abranger a maior parte dos trabalhos relacionados à $\mathrm{ME}$ atualmente encontrada nos mais importantes periódicos nacionais e internacionais da área da Gestão da Produção. Também desenvolvemos um sistema de classificação, com o qual estruturamos a própria revisão da literatura. Tomou-se muito cuidado para não confundir ME com just in time. Entendemos que o just in time (JIT) é um princípio dentro do paradigma enxuto. Assim, trabalhos desenvolvidos somente sob uma ótica do JIT, sem estar diretamente relacionado à ME, foram excluídos deste estudo. Vários autores aceitam a afirmação de que o JIT é um princípio da ME, dentre eles Ahlstron \& Karlsson (1996), Henderson \& Larco (2000) e Sanchez \& Perez (2001). Nas palavras de Ghinato (1995), "o JIT é somente um meio para se alcançar o verdadeiro objetivo do Sistema Toyota de Produção que é o de aumentar o lucro através da completa eliminação dos desperdícios". Uma revisão completa, embora não atualizada, sobre JIT pode ser encontrada em Moras et al. (1991).

A importância das classificações dentro da atividade científica é clara, visto que o conhecimento científico se baseia na classificação. Portanto, a realização de uma classificação é ferramenta essencial para o conhecimento de determinada área.

Para Good (1965), as classificações podem servir para os seguintes propósitos: i) conhecimento mental e comunicação; ii) descoberta de novo campo de pesquisa; iii) planejamento de estrutura organizacional ou estrutura de máquina; iv) lista de conferência; v) entretenimento.

A classificação que será apresentada neste trabalho se encontra principalmente nos grupos (i) e (ii), a qual servirá para maior conhecimento do tema ME, além de propor pontos importantes para serem estudados em futuras pesquisas.

Nossa classificação se baseia em quatro parâmetros: a metodologia usada, a abrangência, os princípios e os capacitadores da ME discutidos.

Estruturamos este trabalho da seguinte forma: na seção 2 apresentamos a metodologia; na seção 3, o sistema de classificação de trabalhos e como este foi utilizado para classificar os artigos encontrados na revisão; na seção 4 apresentamos a revisão da literatura sobre ME, devidamente estruturada de acordo com a classificação anterior; na seção 5 fazemos uma análise geral da ME; e, finalmente, na seção 6 , tecemos algumas conclusões e sugerimos novos temas de pesquisas dentro da ME.

\section{Metodologia}

Este trabalho é do tipo teórico-conceitual e realiza uma revisão bibliográfica sobre estudos que falam sobre a ME. Para isso, é utilizada a estrutura metodológica proposta por Godinho Filho \& Fernandes (2003). Essa estrutura é mostrada na Figura 1, na qual podemos notar que a realização de uma revisão sobre ME deve ser o passo inicial para este tipo de trabalho. Em nosso estudo realizamos uma pesquisa sobre ME utilizando diversas bases de dados (COMPENDEX, INSPEC, entre outras). Foram encontrados 82 artigos sobre ME. Em seguida desenvolvemos um sistema de classificação (detalhado na seção 3) que se baseia em quatro parâmetros principais: metodologia, abrangência, princípios e ferramentas. Proposto o sistema de classificação, este foi utilizado para classificar os artigos da revisão (seção 3). Assim pôde-se estruturar a revisão bibliográfica da forma mais conveniente (seção 4) e também realizar a análise geral da ME (seção 5). Essa análise possibilita melhor conhecimento do tema ME e sugere futuras pesquisas (seções 5 e 6 ).

\section{Classificação da literatura sobre Manufatura Enxuta}

\subsection{O sistema de classificação proposto}

Apresentamos nesta seção o sistema de classificação propriamente dito. Esse sistema baseia-se em quatro categorias principais:

- a metodologia usada;

- a abrangência;

- os princípios da ME enfatizados;

- os capacitadores da ME discutidos.

Para facilitar a classificação dos trabalhos, faremos uma codificação para cada atributo que as categorias assumirem.

A primeira categoria do sistema de classificação proposto é a metodologia usada no trabalho. Filippine (1997), Fernandes (1999) e Berto \& Nakano (1998, 1999, 2000) dividem os procedimentos de pesquisa mais utilizados na área de Gestão da Produção em cinco classes: teóricoconceitual, experimental, pesquisa de avaliação (survey), estudo de caso e pesquisa-ação. Para este trabalho, dividimos os procedimentos, assim, a categoria metodologia, 
de nosso sistema de classificação, foi separada em duas grandes classes:

- Trabalhos teóricos (representaremos esta classe pela letra T) - dentro desta classe estão os trabalhos que utilizam metodologia científica baseada na teoria, ou seja, pesquisas do tipo teórico-conceitual, como discussões conceituais e revisões da literatura.

- Trabalhos práticos (representaremos esta classe pela letra P) - dentro desta classe estão todos os outros procedimentos de pesquisa citados por Filippine (1997), Fernandes (1999) e Berto \& Nakano (1998, 1999, 2000): pesquisas do tipo experimental, surveys, estudos de caso e pesquisa-ação. Todas utilizam a prática para testar ou validar algum conceito determinado.

A segunda categoria do sistema de classificação proposto é a abrangência do trabalho. Essa categoria referese basicamente ao nível da cadeia de suprimentos em que está focado o trabalho sobre ME. A criação dessa categoria justifica-se pelo fato de que a Manufatura Enxuta, apesar de ter nascido em chão de fábrica, como o próprio nome mostra, evoluiu para outras áreas da cadeia de suprimentos; nas palavras de Warnecke \& Hüser (1995): "A produção propriamente dita é somente um aspecto da ME". Esses autores identificam aspectos da ME relacionados a quatro áreas: desenvolvimento de produto, cadeia de suprimentos, chão de fábrica e serviço de pós-venda. Para Panizzolo (1998), muitos autores, em razão do aumento do escopo da ME, chegaram a sugerir o termo Empresa Enxuta em vez de somente Manufatura Enxuta. A segunda categoria de nosso sistema de classificação compreende exatamente esta questão. Assim, quanto à abrangência, dividiremos os trabalhos em três grandes classes:

- foco no chão de fábrica (representaremos esta classe pelas letras CF) - refere-se aos trabalhos cujo foco principal é o estudo das práticas enxutas no chão de fábrica;

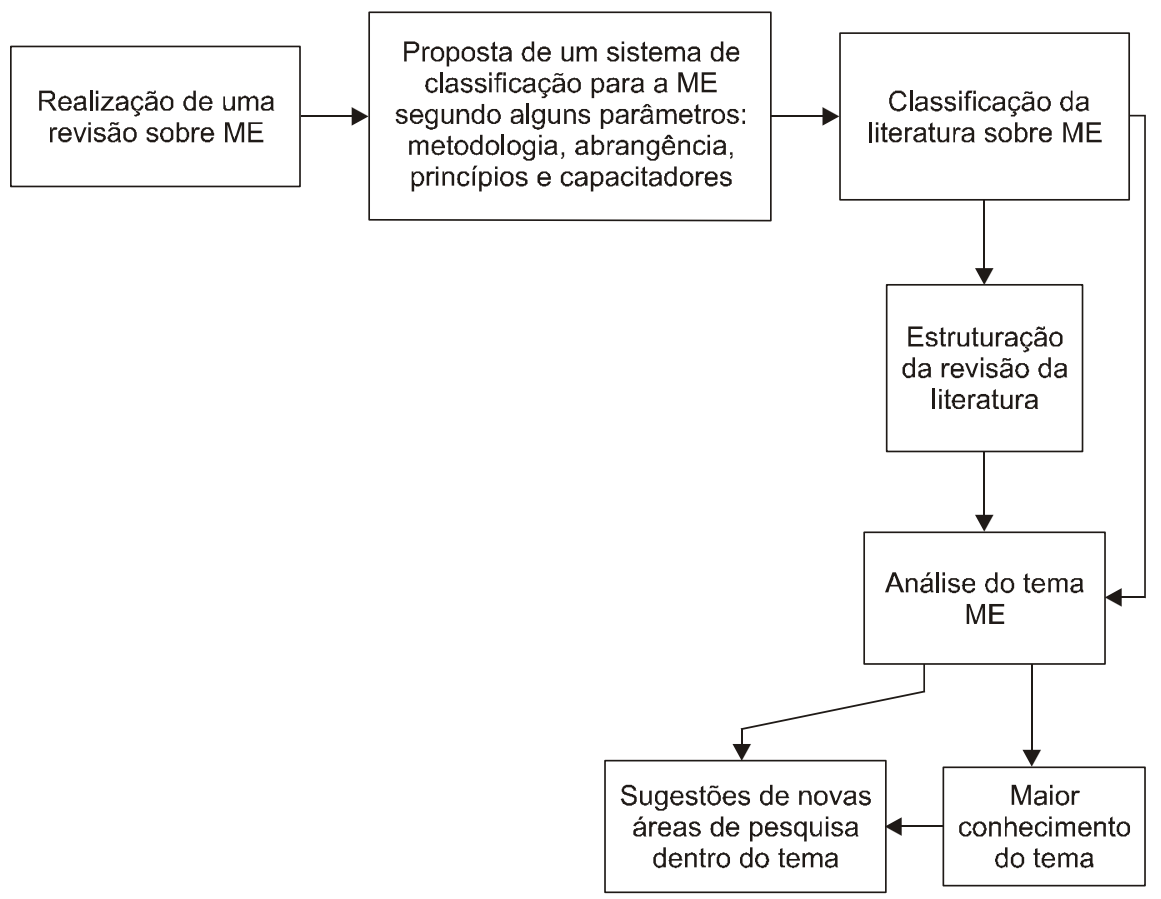

Figura 1 - Estrutura metodológica do trabalho. Fonte: Adaptado de Godinho Filho \& Fernandes (2003). 
- foco em outras áreas da empresa (representaremos esta classe pelas letras OA) - refere-se aos trabalhos cujo foco principal é o estudo das práticas enxutas em outras áreas da organização (projeto, recursos humanos, contabilidade/custos, etc.). Esta classe engloba as áreas desenvolvimento de produto e serviço pós-venda citados por Warnecke \& Hüser (1995);

- foco na cadeia de suprimentos (representaremos esta classe pelas letras CS) - refere-se a trabalhos cujo foco principal são as práticas enxutas relacionadas a clientes e fornecedores da empresa.

A terceira categoria do sistema de classificação são os princípios enxutos enfatizados no trabalho. Para este trabalho extraímos de importantes referências sobre Manufatura Enxuta e Sistema Toyota de Produção (Monden, 1984; Shingo, 1985; Robinson, 1990; Shingo, 1996a; Shingo, 1996b; Ohno, 1997; Womack \& Jones, 1998; Henderson \& Larco, 2000) os princípios mais importantes da ME. A Tabela 1 mostra esses princípios com seus respectivos códigos do sistema de classificação.

Finalmente, a quarta categoria do sistema de classificação proposto são os capacitadores (tecnologias, metodologias e ferramentas) da ME. A partir das referências citadas anteriormente e da própria revisão realizada sobre o tema $\mathrm{ME}$, foram identificadas as principais tecnologias, ferramentas e metodologias necessárias para conseguir um sistema enxuto nas empresas. Também a partir da revisão, pode-se organizar os capacitadores de acordo com o princípio (representado pelo código mostrado na Tabela 1) que está mais relacionado. Isto é mostrado na Tabela 2.

\subsection{Classificação da revisão bibliográfica sobre ME}

Após apresentarmos a estrutura do sistema de classificação, vamos para a classificação propriamente dita. A revisão bibliográfica foi composta de 82 trabalhos sobre
ME. Uma observação é de extrema importância: a revisão buscou somente trabalhos que tratam claramente do assunto Manufatura Enxuta, não se preocupando com trabalhos que tratam apenas de algum princípio ou capacitador específico da ME, como just in time, seis sigma, entre outros.

A classificação, quanto às quatro categorias mostradas na seção anterior, é apresentada na Tabela 3. Os artigos estão em ordem cronológica e alfabética dentro do ano de publicação.

A Figura 2 mostra os artigos da revisão divididos de acordo com a referência (artigos técnicos, proceedings e periódicos) e ano de publicação. Pode-se observar que há forte predominância de artigos publicados em periódicos científicos, que começaram a ser publicados em 1993. Há grande variação no número destes artigos: um pico maior em 1996, outros em 1997 e 2000 e provavelmente ocorrerão novos picos em 2004 ou nos próximos anos, ou seja, a Manufatura Enxuta é um tema que não está esgotado.

\section{A revisão da literatura sobre Manufatura Enxuta}

Nesta seção estruturamos a revisão bibliográfica sobre ME utilizando a classificação da seção anterior, mais especificamente as duas primeiras categorias: metodologia e abrangência. Quanto à metodologia, a divisão é simples e segue a classificação: trabalhos práticos e teóricos. Já quanto à abrangência, pode-se encontrar na revisão trabalhos que se limitam a explorar somente um nível da ME (seja ele chão de fábrica, outras áreas da empresa ou cadeia de suprimentos) e outros mais abrangentes, que estudam aspectos da ME relacionados a dois desses níveis e até mesmo aos três em conjunto. É exatamente dessa forma que estruturamos as seções que seguem. Apresentamos um breve resumo de cada trabalho, tentando ilustrar as principais contribuições para a literatura sobre ME.

Tabela 1 - Princípios mais importantes da Manufatura Enxuta.

\begin{tabular}{lc}
\hline \multicolumn{1}{c}{ Princípio } & Código \\
\hline Determinar valor para o cliente, identificando cadeia de valor e eliminando desperdícios & A \\
Trabalho em fluxo/simplificar fluxo & $\mathrm{B}$ \\
Produção puxada/just in time & $\mathrm{C}$ \\
Busca da perfeição & $\mathrm{D}$ \\
Autonomação/qualidade seis sigma & $\mathrm{E}$ \\
Limpeza, ordem e segurança & $\mathrm{F}$ \\
Desenvolvimento e capacitação de recursos humanos & $\mathrm{G}$ \\
Gerenciamento visual & $\mathrm{H}$ \\
Adaptação de outras áreas da empresa ao pensamento enxuto & $\mathrm{I}$ \\
\hline
\end{tabular}


Tabela 2 - Os capacitadores da ME, sua respectiva codificação e relacionamento com princípios enxutos. Fonte: Revisão bibliográfica sobre ME.

\begin{tabular}{|c|c|c|}
\hline Capacitadores (tecnologias, metodologias e ferramentas) & Código & Princípio relacionado \\
\hline Mapeamento do fluxo de valor & 1 & A \\
\hline Melhoria na relação cliente-fornecedor/redução do número de fornecedores & 2 & A \\
\hline Recebimento/fornecimento just in time & 3 & $\mathrm{~A}, \mathrm{C}$ \\
\hline Tecnologia de grupo & 4 & $\mathrm{~B}$ \\
\hline Trabalho em fluxo contínuo (one piece flow)/redução tamanho de lote & 5 & B \\
\hline Trabalhar de acordo com o takt time/produção sincronizada & 6 & B \\
\hline Manutenção produtiva total (TPM) & 7 & B \\
\hline Kanban & 8 & $\mathrm{C}$ \\
\hline Redução do tempo de set up & 9 & $\mathrm{C}$ \\
\hline Kaizen & 10 & $\mathrm{D}$ \\
\hline Ferramentas de controle da qualidade & 11 & $\mathrm{E}$ \\
\hline Zero defeito & 12 & $\mathrm{E}$ \\
\hline Ferramentas poka yoke & 13 & $\mathrm{E}$ \\
\hline $5 \mathrm{~S}$ & 14 & $\mathrm{~F}$ \\
\hline Empowerment & 15 & G \\
\hline Trabalho em equipes & 16 & G \\
\hline Comprometimento dos funcionários e da alta gerência & 17 & G \\
\hline Trabalhador multi-habilitado/rodízio de funções & 18 & G \\
\hline Treinamento de pessoal & 19 & G \\
\hline Medidas de performance/balanced scorecard & 20 & $\mathrm{H}$ \\
\hline Gráficos de controle visuais & 21 & $\mathrm{H}$ \\
\hline Modificação de estrutura financeira/custos & 22 & I \\
\hline Ferramentas para projeto enxuto (DFMA, etc.) & 23 & I \\
\hline
\end{tabular}

Tabela 3 - Classificação dos artigos da revisão sobre ME.

\begin{tabular}{|c|c|c|c|c|}
\hline Artigo/ano de publicação & $\begin{array}{c}\text { Classificação } \\
\text { quanto à } \\
\text { metodologia }\end{array}$ & $\begin{array}{c}\text { Classificação } \\
\text { quanto à } \\
\text { abrangência }\end{array}$ & $\begin{array}{c}\text { Classificação } \\
\text { quanto aos } \\
\text { princípios } \\
\text { enxutos }\end{array}$ & $\begin{array}{l}\text { Classificação } \\
\text { quanto aos } \\
\text { capacitadores } \\
\text { enxutos }\end{array}$ \\
\hline Jacobs \& Meerkov (1993) & $\mathrm{T}$ & $\mathrm{CF}$ & $\mathrm{B}, \mathrm{C}$ & 5 \\
\hline Barker (1994) & $\mathrm{P}$ & $\mathrm{CF}, \mathrm{CS}$ & $\mathrm{A}, \mathrm{B}, \mathrm{C}$ & $1,4,5,8,9$ \\
\hline Billesbach (1994) & $P$ & $\mathrm{CF}, \mathrm{OA}$ & $\begin{array}{c}\mathrm{A}, \mathrm{B}, \mathrm{C}, \mathrm{D}, \mathrm{E}, \mathrm{G}, \\
\mathrm{H}, \mathrm{I}\end{array}$ & $\begin{array}{c}6,7,8,10,16,17 \\
19,21\end{array}$ \\
\hline Toomey (1994) & $\mathrm{T}$ & $\mathrm{OA}$ & I & 22 \\
\hline Dong (1995) & $\mathrm{P}$ & CS & $\mathrm{C}, \mathrm{E}$ & \\
\hline Ghinard (1995) & $\mathrm{T}$ & $\mathrm{CF}$ & $\mathrm{C}, \mathrm{E}$ & $8,11,12,13$ \\
\hline Johnston (1995) & $\mathrm{P}$ & $\mathrm{CF}$ & $\mathrm{B}, \mathrm{C}, \mathrm{E}, \mathrm{G}$ & $4,8,16$ \\
\hline Karlsson \& Ahlströn (1995) & $\mathrm{P}$ & $\mathrm{OA}$ & I & 22 \\
\hline Kosonen \& Buhanist (1995) & $\mathrm{P}$ & $\mathrm{CF}, \mathrm{OA}$ & $\mathrm{G}, \mathrm{I}$ & 16,19 \\
\hline Lang \& Hugge (1995) & $\mathrm{P}$ & $\mathrm{CF}, \mathrm{OA}$ & $\mathrm{B}, \mathrm{C}, \mathrm{E}, \mathrm{I}$ & $4,11,23$ \\
\hline Wardt (1995) & $\mathrm{P}$ & $\mathrm{CF}$ & $\mathrm{A}, \mathrm{D}, \mathrm{G}$ & $2,10,18$ \\
\hline Warnecke \& Huser (1995) & $\mathrm{T}$ & $\mathrm{CF}, \mathrm{OA}, \mathrm{CS}$ & $\mathrm{A}, \mathrm{B}, \mathrm{G}$ & $2,4,15,16$ \\
\hline Ahlströn \& Karlsson (1996) & $\mathrm{P}$ & OA & I & 22 \\
\hline Boyer (1996) & $\mathrm{P}$ & $\mathrm{OA}$ & $\mathrm{G}, \mathrm{I}$ & $15,16,17,19$ \\
\hline Braiden \& Morrison (1996) & $\mathrm{P}$ & $\mathrm{CF}$ & $\mathrm{B}, \mathrm{C}, \mathrm{E}$ & 5 \\
\hline De Toni \& Tonchia (1996) & $\mathrm{P}$ & $\mathrm{CF}, \mathrm{CS}$ & $\mathrm{D}, \mathrm{G}$ & $10,16,17$ \\
\hline Dupernex \& Relph (1996) & $\mathrm{T}$ & $\mathrm{CF}$ & $\mathrm{B}, \mathrm{C}$ & 5,9 \\
\hline Edwards (1996) & $\mathrm{T}$ & $\mathrm{CF}$ & $\mathrm{B}, \mathrm{C}, \mathrm{E}, \mathrm{G}$ & $\begin{array}{c}4,5,6,7,15,16 \\
18\end{array}$ \\
\hline
\end{tabular}


Tabela 3 - Classificação dos artigos da revisão sobre ME. (Continuação.)

\begin{tabular}{|c|c|c|c|c|}
\hline Artigo/ano de publicação & $\begin{array}{l}\text { Classificação } \\
\text { quanto à } \\
\text { metodologia }\end{array}$ & $\begin{array}{l}\text { Classificação } \\
\text { quanto à } \\
\text { abrangência }\end{array}$ & $\begin{array}{l}\text { Classificação } \\
\text { quanto aos } \\
\text { princípios } \\
\text { enxutos }\end{array}$ & $\begin{array}{l}\text { Classificação } \\
\text { quanto aos } \\
\text { capacitadores } \\
\text { enxutos }\end{array}$ \\
\hline Forza (1996) & $\mathrm{P}$ & $\mathrm{CF}, \mathrm{OA}$ & $\mathrm{G}, \mathrm{I}$ & $15,16,17,19$ \\
\hline Karlsson \& Ahlströn (1996) & $\mathrm{T}$ & $\mathrm{CF}, \mathrm{OA}$ & $\mathrm{B}, \mathrm{C}, \mathrm{D}, \mathrm{E}, \mathrm{G}$ & $5,8,10,11,12$ \\
\hline Katayama \& Bennett (1996) & $\mathrm{P}$ & $\mathrm{CF}, \mathrm{CS}$ & $\mathrm{B}, \mathrm{C}, \mathrm{D}, \mathrm{F}, \mathrm{G}$ & $\begin{array}{l}3,4,6,7,8,10 \\
14,18\end{array}$ \\
\hline Lamming (1996) & $\mathrm{T}$ & $\mathrm{CS}$ & $\mathrm{A}, \mathrm{B}, \mathrm{C}$ & 2,3 \\
\hline Mabry \& Morrison (1996) & $\mathrm{P}$ & $\mathrm{CF}$ & $\mathrm{B}, \mathrm{C}$ & $4,5,6$ \\
\hline Niepce \& Molleman (1996) & $\mathrm{P}$ & OA & $\mathrm{G}, \mathrm{I}$ & $15,16,19$ \\
\hline Oliver et al. (1996) & $\mathrm{P}$ & $\mathrm{CF}, \mathrm{CS}$ & $\begin{array}{l}\text { A, B, C, D, E, } \\
\text { G, H }\end{array}$ & $12,13,16,21$ \\
\hline Schuring (1996) & $\mathrm{P}$ & $\mathrm{CF}$ & G & 16 \\
\hline Sohal (1996) & $\mathrm{P}$ & $\mathrm{CF}, \mathrm{OA}$ & $\mathrm{C}, \mathrm{G}, \mathrm{I}$ & $\begin{array}{l}8,9,15,16 \\
19,23\end{array}$ \\
\hline Womack \& Jones (1996) & $\mathrm{T}$ & OA & $\mathrm{G}, \mathrm{I}$ & $17,18,19,23$ \\
\hline Harisson (1997) & $\mathrm{T}$ & $\mathrm{CF}$ & $\mathrm{B}, \mathrm{C}$ & 5,9 \\
\hline Hines \& Rich (1997) & $\mathrm{T}$ & $\mathrm{CF}, \mathrm{CS}$ & A & 1 \\
\hline James-Moore \& Gibbons (1997) & $\mathrm{P}$ & $\mathrm{CF}$ & A, C, E, F, G & $\begin{array}{l}2,7,11,13,14 \\
15,16,17\end{array}$ \\
\hline Juliard (1997) & $\mathrm{P}$ & $\mathrm{CF}, \mathrm{CS}$ & $\mathrm{A}, \mathrm{B}, \mathrm{C}, \mathrm{D}, \mathrm{G}$ & $2,4,8,9,16$ \\
\hline Kochan \& Lansburry (1997) & $P$ & $\mathrm{CF}, \mathrm{OA}$ & $\mathrm{G}, \mathrm{I}$ & $15,16,19,22$ \\
\hline Maccoby (1997) & $\mathrm{T}$ & $\mathrm{OA}$ & G & $15,16,17$ \\
\hline Macduffie \& Helper (1997) & $\mathrm{P}$ & CS & $\mathrm{A}, \mathrm{B}, \mathrm{C}, \mathrm{D}, \mathrm{E}$ & $11,16,19$ \\
\hline Narayanaswany (1997) & $\mathrm{T}$ & $\mathrm{CF}$ & $\mathrm{B}$ & 4 \\
\hline Steiner (1997) & $\mathrm{T}$ & $\mathrm{CS}$ & A & 2 \\
\hline Zayko et al. (1997) & $\mathrm{P}$ & $\mathrm{CF}$ & $\mathrm{B}, \mathrm{E}, \mathrm{G}$ & 4,18 \\
\hline Ahlströn (1998) & $\mathrm{P}$ & $\mathrm{CF}$ & $\mathrm{A}, \mathrm{C}, \mathrm{D}, \mathrm{E}, \mathrm{G}$ & $8,10,12,15,16$ \\
\hline Brown (1998) & $\mathrm{P}$ & $\mathrm{CF}$ & $\mathrm{E}, \mathrm{G}$ & 11,17 \\
\hline Duggan (1998) & $\mathrm{T}$ & $\mathrm{CF}$ & B & 4 \\
\hline Erridge \& Murray (1998) & $\mathrm{P}$ & $\mathrm{CS}$ & $\mathrm{A}, \mathrm{C}$ & 2,3 \\
\hline Hancock \& Zayko (1998) & $\mathrm{T}$ & $\mathrm{CF}$ & $\mathrm{B}, \mathrm{C}, \mathrm{E}, \mathrm{G}, \mathrm{I}$ & $\begin{array}{l}5,6,7,8,9,12 \\
18,19\end{array}$ \\
\hline Kochan (1998) & $\mathrm{P}$ & $\mathrm{CF}$ & $\mathrm{C}, \mathrm{E}$ & 8,11 \\
\hline Panizzolo (1998) & $\mathrm{P}$ & $\mathrm{CF}, \mathrm{OA}, \mathrm{CS}$ & $\begin{array}{l}\text { A, B, C, E, } \\
\text { G, H, I }\end{array}$ & $\begin{array}{l}2,6,8,9,13,16, \\
18,21,23\end{array}$ \\
\hline Reynolds (1998) & $\mathrm{T}$ & $\mathrm{CF}$ & B & $4,5,6$ \\
\hline Hampson (1999) & $\mathrm{P}$ & $\mathrm{CF}$ & B.D & 6,10 \\
\hline Ivezic et al. (1999) & $\mathrm{T}$ & $\mathrm{CF}$ & $\mathrm{B}, \mathrm{C}, \mathrm{G}$ & $5,16,18$ \\
\hline Katayama \& Bennett (1999) & $\mathrm{P}$ & $\mathrm{CF}$ & $\mathrm{C}, \mathrm{E}$ & 7 \\
\hline Muffatto (1999) & $\mathrm{T}$ & $\mathrm{CF}$ & $C, D, E, G$ & $10,15,16,18$ \\
\hline Naylor et al. (1999) & $\mathrm{P}$ & $\mathrm{CF}, \mathrm{CS}$ & $\mathrm{C}$ & 3,8 \\
\hline Shahmanesh (1999) & $\mathrm{P}$ & $\mathrm{CF}$ & $\mathrm{A}, \mathrm{D}$ & 1,10 \\
\hline Spear \& Bowen (1999) & $\mathrm{P}$ & $\mathrm{CF}, \mathrm{CS}$ & $\mathrm{A}, \mathrm{B}, \mathrm{C}, \mathrm{D}, \mathrm{G}$ & $5,9,10,16,19$ \\
\hline Storch \& Lim (1999) & $\mathrm{P}$ & $\mathrm{CF}$ & $\mathrm{B}, \mathrm{C}$ & $4,5,6,8$ \\
\hline Allen (2000) & $\mathrm{P}$ & $\mathrm{CF}$ & $\mathrm{B}, \mathrm{C}, \mathrm{F}$ & $4,5,6,7,14$ \\
\hline
\end{tabular}


Tabela 3 - Classificação dos artigos da revisão sobre ME. (Continuação.)

\begin{tabular}{|c|c|c|c|c|}
\hline Artigo/ano de publicação & $\begin{array}{c}\text { Classificação } \\
\text { quanto à } \\
\text { metodologia }\end{array}$ & $\begin{array}{c}\text { Classificação } \\
\text { quanto à } \\
\text { abrangência }\end{array}$ & $\begin{array}{c}\text { Classificação } \\
\text { quanto aos } \\
\text { princípios } \\
\text { enxutos }\end{array}$ & $\begin{array}{l}\text { Classificação } \\
\text { quanto aos } \\
\text { capacitadores } \\
\text { enxutos }\end{array}$ \\
\hline Bamber \& Dale (2000) & $\mathrm{P}$ & $\mathrm{CF}, \mathrm{OA}, \mathrm{CS}$ & $\mathrm{A}, \mathrm{B}, \mathrm{C}, \mathrm{G}, \mathrm{I}$ & $2,4,8,16,17,19$, \\
\hline Biazzo \& Panizzolo (2000) & $\mathrm{T}$ & $\mathrm{OA}$ & $\mathrm{G}, \mathrm{I}$ & $15,16,18,19$ \\
\hline Dennis et al. (2000) & $\mathrm{P}$ & $\mathrm{CS}$ & A & 1 \\
\hline Detty \& Yingling (2000) & $\mathrm{P}$ & $\mathrm{CF}$ & $\mathrm{B}, \mathrm{C}, \mathrm{E}, \mathrm{F}$ & $3,4,5,8,13,14$ \\
\hline Knuf (2000) & $\mathrm{T}$ & $\mathrm{OA}$ & G & 16,17 \\
\hline Lewis (2000) & $\mathrm{P}$ & $\mathrm{CF}, \mathrm{OA}, \mathrm{CS}$ & $\mathrm{A}, \mathrm{B}, \mathrm{C}, \mathrm{E}, \mathrm{G}, \mathrm{H}$ & $\begin{array}{c}2,4,8,9,11,12 \\
16,20\end{array}$ \\
\hline Maskell (2000) & $\mathrm{T}$ & OA & I & 22 \\
\hline Mason-Jones et al. (2000) & $\mathrm{P}$ & $\mathrm{CF}, \mathrm{CS}$ & $\mathrm{B}, \mathrm{C}, \mathrm{E}$ & $4,8,11$ \\
\hline Pérez \& Sanchéz (2000) & $\mathrm{P}$ & $\mathrm{OA}, \mathrm{CS}$ & $\mathrm{A}, \mathrm{C}, \mathrm{G}$ & $2,3,16,18,19$ \\
\hline Alvarez \& Antunes Jr. (2001) & $\mathrm{T}$ & $\mathrm{CF}$ & B & 6 \\
\hline Arkader (2001) & $\mathrm{P}$ & $\mathrm{CS}$ & A & 2,3 \\
\hline Bicheno et al. (2001) & $\mathrm{P}$ & $\mathrm{CF}, \mathrm{CS}$ & $\mathrm{A}, \mathrm{B}, \mathrm{C}$ & $5,7,8$ \\
\hline Gulyani (2001) & $\mathrm{P}$ & $\mathrm{CS}$ & $\mathrm{C}$ & 3 \\
\hline Nellore et al. (2001) & $\mathrm{P}$ & $\mathrm{CS}$ & $\mathrm{A}, \mathrm{C}, \mathrm{D}$ & $2,3,8,10$ \\
\hline Sanchéz \& Pérez (2001) & $\mathrm{P}$ & $\mathrm{CF}, \mathrm{CS}$ & $\mathrm{A}, \mathrm{B}, \mathrm{C}, \mathrm{D}, \mathrm{G}$ & $\begin{array}{c}2,3,4,5,7,9,16 \\
17,18,19\end{array}$ \\
\hline White \& Prybutok (2001) & $\mathrm{P}$ & $\mathrm{CF}$ & $\mathrm{B}, \mathrm{C}, \mathrm{E}, \mathrm{G}$ & $\begin{array}{c}3,4,7,8,9,11 \\
18\end{array}$ \\
\hline Arbós (2002) & $\mathrm{P}$ & $\mathrm{CF}, \mathrm{OA}$ & $\mathrm{A}, \mathrm{B}, \mathrm{G}$ & $\begin{array}{c}6,7,15,16,17 \\
18,19\end{array}$ \\
\hline Nave (2002) & $\mathrm{T}$ & $\mathrm{CF}, \mathrm{CS}$ & $\mathrm{A}, \mathrm{B}, \mathrm{C}, \mathrm{D}$ & 1 \\
\hline Soriano-Meier \& Forrester (2002) & $\mathrm{P}$ & $\mathrm{CF}$ & $\mathrm{A}, \mathrm{C}, \mathrm{D}, \mathrm{E}, \mathrm{G}$ & $3,10,12,16,18$ \\
\hline Sullivan et al. (2002) & $\mathrm{P}$ & $\mathrm{CS}$ & $\mathrm{A}, \mathrm{C}, \mathrm{D}, \mathrm{E}$ & $1,8,9,10$ \\
\hline Shah \& Ward (2002) & $\mathrm{P}$ & $\mathrm{CF}$ & $\mathrm{B}, \mathrm{C}, \mathrm{D}, \mathrm{E}, \mathrm{G}$ & $\begin{array}{c}4,5,7,8,9,10 \\
16,18\end{array}$ \\
\hline Vincenti (2002) & $\mathrm{P}$ & CS & $\mathrm{D}$ & 10 \\
\hline Yusuf \& Adeleye (2002) & $\mathrm{P}$ & $\mathrm{CF}, \mathrm{CS}$ & $\mathrm{A}, \mathrm{B}, \mathrm{C}, \mathrm{E}, \mathrm{G}$ & $\begin{array}{c}2,5,7,8,9,16 \\
18\end{array}$ \\
\hline Kojima \& Kaplinsky (2003) & $\mathrm{P}$ & $\mathrm{CF}$ & $\mathrm{A}, \mathrm{B}, \mathrm{C}, \mathrm{D}, \mathrm{E}, \mathrm{G}$ & $\begin{array}{c}3,4,5,8,9,10 \\
11,16,17,18,19\end{array}$ \\
\hline Prince \& Kay (2003) & $\mathrm{P}$ & $\mathrm{CF}$ & $\mathrm{B}$ & 4 \\
\hline Stratton \& Warburton (2003) & $\mathrm{P}$ & $\mathrm{CF}, \mathrm{CS}$ & A, B & $2,5,6$ \\
\hline Bruun \& Mefford (2004) & $\mathrm{P}$ & $\mathrm{CF}, \mathrm{OA}, \mathrm{CS}$ & $\mathrm{A}, \mathrm{B}, \mathrm{C}, \mathrm{D}, \mathrm{G}, \mathrm{I}$ & $\begin{array}{c}2,5,9,10,16,17, \\
22,23\end{array}$ \\
\hline
\end{tabular}

\subsection{Trabalhos práticos $(\mathrm{P})$}

\subsubsection{Trabalhos com foco no chão de fábrica (CF)}

Johnston (1995) analisa um estudo de caso sobre experiências e dificuldades de uma empresa na adoção de sistemas de gestão auxiliados por computador (tipo MRP). $\mathrm{O}$ autor conclui que a ME ajuda na introdução desses sistemas. Braiden \& Morrison (1996) descrevem os esforços de empresa do setor automobilístico em aumentar a capacidade produtiva utilizando métodos da ME. Outros autores trabalham com a manufatura enxuta dentro da indústria automobilística: Mabry \& Morrison (1996) descrevem a adoção de algumas técnicas enxutas na Delphi, enquanto Kochan (1998) mostra o uso de técnicas enxutas em uma fábrica européia da Mercedes que produz o modelo Classe A.

Já o estudo da ME em empresas específicas, com características diferentes da aplicação clássica (indústria automobilística), pode ser visto em pelo menos seis trabalhos desta categoria: Zayko et al. (1997) mostram evidências de que também em pequenas empresas a ME traz grandes melhorias para a manufatura; James-Moore \& Gibbons (1997) estudam a adoção de métodos e práticas da ME em 
empresas caracterizadas pela alta variedade de produtos e baixo volume de produção unitária (indústria aeroespacial e civil), comparando com os métodos e práticas enxutas clássicas (indústria automobilística); Storch \& Lim (1999) estudam a ME nesse mesmo tipo de empresa (no caso, indústria de navios), focando seu trabalho na metodologia para manutenção do fluxo do valor nesse tipo de empresa; White \& Prybutok (2001) realizam um estudo da relação entre ME e o tipo de sistema de produção; Wardt (1995) apresenta a aplicação de práticas enxutas na indústria da construção de poços; e, finalmente, Shah \& Ward (2002) examinam, por meio do estudo de múltiplos casos, o efeito de três fatores distintos: tamanho da empresa, idade e atuação dos sindicatos na implementação da ME.

Já Brown (1998) realiza um estudo de múltiplos casos sobre relações entre qualidade, comprometimento da gerência e estratégia. Esse estudo conclui basicamente que uma visão estratégica e um grande comprometimento da gerência melhoram muito a performance das técnicas e ferramentas da qualidade dentro do contexto da ME. Outro autor que estuda o aspecto qualidade da ME é Shahmanesh (1999), mostrando o kaizen, dentro da ME, em uma empresa automobilística. Dois autores focam os aspectos da implementação da ME em empresas: Ahlström (1998) propõe uma sequiência melhor de implementação da ME, deixando claro que algumas atividades devem ser realizadas em paralelo; e Allen (2000) realiza alguns estudos de caso e comprova que cada implantação da ME é única, cabendo à empresa escolher qual princípio deve enfatizar, de acordo com seus objetivos estratégicos.

Katayama \& Bennett (1999) comparam a ME com outros dois importantes conceitos dentro da Gestão da Produção, a Manufatura Ágil e a Manufatura Adaptável (este último proposto pelos mesmos autores em Katayama \& Bennett, 1996) dentro do contexto japonês. Os resultados mostram que as empresas japonesas estão tentando alcançar adaptabilidade por meio de atividades ágeis. Também Prince \& Kay (2003) trabalham com a relação ME e Manufatura Ágil. Esses autores propõem uma metodologia em que alguns princípios enxutos e ágeis trabalham em conjunto. Hampson (1999) trabalha com a necessidade de balanceamento entre os conceitos enxutos da produção sincronizada e da melhoria contínua para que a força de trabalho não se sinta sobrecarregada. Schuring (1996) analisa o papel do trabalho em equipe na ME. Detty \& Yingling (2000) trabalham com a simulação para quantificar os benefícios da adoção de várias técnicas enxutas. Dois estudos desenvolvem e aplicam metodologias para avaliar o nível de adoção da ME em um setor industrial: Soriano-Meier \& Forrester (2002) e Kojima \& Kaplinsky (2003).

\subsubsection{Trabalhos com foco em outras áreas da empresa (OA)}

Nesta categoria temos basicamente dois tipos de trabalhos: os que tratam da relação ME e sistemas contábeis/ financeiros e os que tratam da relação $\mathrm{ME}$ e recursos humanos. Karlsson \& Ahlstrom (1995) propõem um novo sistema de remuneração baseado nos objetivos da ME, modelo este que é verificado por meio de um estudo de caso. Esses autores concluem que este novo sistema tem importante papel na introdução e na melhoria da eficiência da ME. Esses mesmos autores estudam, em outro trabalho (Ahlström \& Karlsson, 1996), o papel do sistema de contabilidade gerencial na ME, concluindo que este é fundamental no estabelecimento de uma estratégia enxuta nas empresas. Niepce \& Molleman (1996) estudam o papel do trabalhador na ME e em sistemas sociotécnicos, estabelecendo, com base em estudos de caso, diferenças e semelhanças para ambos. Já Boyer (1996) focaliza seu trabalho no estudo da relação entre o comprometimento da empresa com a ME e as ações tomadas pela gerência para desenvolver habilidades e treinar trabalhadores.

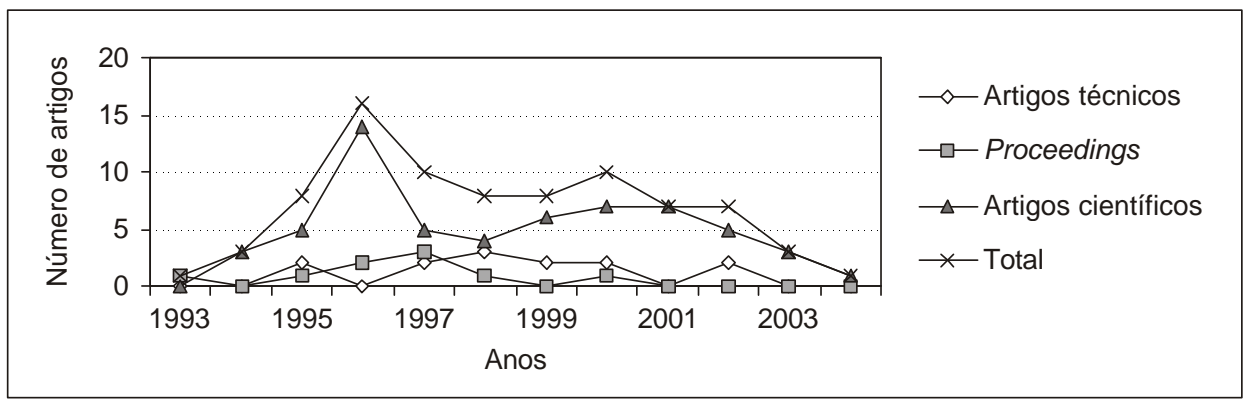

Figura 2 - Quantidade de artigos sobre Manufatura Enxuta. 
Os resultados deste estudo mostram que investir no treinamento e no desenvolvimento dos trabalhadores é um fator determinante para obter os ganhos de produtividade da ME.

\subsubsection{Trabalhos com foco na cadeia de suprimentos (CS)}

Dong (1995) compara a ME e a própria Engenharia de Produção. Em um estudo de caso em uma indústria chinesa, conclui que a aplicação de alguns princípios enxutos, tendo por base algumas técnicas da Engenharia de Produção, gerou uma série de melhorias na empresa. Erridge \& Murray (1998) examinam, em três estudos de caso, a possibilidade de introduzir o fornecimento enxuto em instituições governamentais. E concluem que a maioria dos aspectos do fornecimento enxuto é aplicável, excluindo-se algumas características que devem ser adaptadas a esse tipo de instituição. Arkader (2001) também trabalha com fornecimento enxuto, apresentando as perspectivas atuais dos fornecedores na indústria automobilística brasileira. Macduffie \& Helper (1997) mostram exemplos práticos da difusão de princípios enxutos na cadeia de suprimentos de uma grande empresa automobilística. Gulyani (2001) é outro autor que focaliza seu estudo na indústria automobilística, neste caso, da Índia. Esse autor mostra que os precários meios de transporte do país dificultam a utilização do fornecimento enxuto; porém, as montadoras, para tentar amenizar o problema, estão optando pela formação de clusters industriais. Nellore et al. (2001) destacam a relação entre fornecimento enxuto e compras globais dentro da cadeia de suprimentos. Os resultados do estudo desses autores mostram que o fornecimento enxuto é afetado negativamente pelas compras globais baseadas em preço e que essa estratégia não deve ser usada no fornecimento de peças complexas que necessitam de grande cooperação cliente-fornecedor. Sullivan et al. (2002) mostram um problema de substituição de equipamento dentro do contexto da ME. Esses autores mostram, em um estudo de caso, como o mapeamento do fluxo de valor pode ser usado para mapear o estado atual de uma linha de produção e também para projetar o estado desejado. Vincenti (2002) faz diversas considerações sobre o kaizen, dentro de um contexto de ME, mostrando melhorias que este programa trouxe na cadeia de suprimentos do setor automobilístico. Dennis et al. (2000) trabalham com a análise da cadeia de valor, para identificar ineficiências no processo, e com a simulação, para avaliar programas de melhoria e desenvolver futuros cenários de negócios para a indústria de telecomunicações inglesa.

\subsubsection{Trabalhos com foco no chão de fábrica e em outras áreas da empresa (CF, OA)}

Billesbach (1994) mostra como alguns princípios da ME, aplicados em uma fábrica da DuPont, ajudaram a melhorar vários aspectos da manufatura, dentre eles: estoque em processo e qualidade dos produtos. Lang \& Hugge (1995) também mostram a aplicação de princípios e ferramentas enxutas em uma indústria específica, neste caso, a indústria aeroespacial americana. Kosonen \& Buhanist (1994) focalizam sua pesquisa em como transformar uma empresa em enxuta, respondendo questões como as características necessárias para a mudança, o que a mudança requer e qual o papel do pesquisador no processo de transformação. Esses autores desenvolvem um estudo de caso na indústria de elevadores da Finlândia. Forza (1996) identifica as práticas de organização de trabalho aplicadas na ME testando algumas hipóteses relativas à interação, organização do trabalho e ME em um survey. Os resultados desse estudo mostram que as empresas que adotaram a ME se interessam mais por questões relacionadas à organização do trabalho e pessoas do que as empresas tradicionais. Kochan \& Lansbury (1997) avaliam a organização do trabalho dentro do contexto da ME na indústria de automóveis de diversos países. A conclusão é que, apesar da difusão das técnicas enxutas ao redor do mundo, há uma variação de país para país na maneira da gerência e dos sindicatos se adaptarem às mudanças. Sohal (1996) estuda a implantação de alguns princípios enxutos em uma empresa australiana, concluindo que esta se tornou mais lucrativa e mais competitiva após a aplicação dos princípios. Arbós (2002) propõe uma metodologia para implantar a ME em empresas de serviços.

\subsubsection{Trabalhos com foco no chão de fábrica e na cadeia de suprimentos (CF, CS)}

Barker (1994) apresenta um modelo para o projeto de sistemas de manufatura enxuta por meio de um método baseado no tempo e na capacidade de agregar valor. São mostrados estudos de caso para exemplificar o modelo. Katayama \& Bennett (1996) examinam o papel e a importância da ME dentro do contexto da atual economia recessiva japonesa. Em experiências em quatro empresas, os autores concluem que os métodos enxutos eram competitivos quando a economia japonesa estava em expansão. Atualmente, as empresas japonesas não podem mais confiar nos mesmos conceitos, por isso os autores desenvolveram um novo sistema, que eles denominaram Produção Adaptável, que parece trabalhar melhor com alterações/reduções de demanda do que a ME. Quatro trabalhos nesta categoria estudam o relacionamento entre a ME e a Manufatura Ágil. Naylor et al. (1999) apresentam um novo conceito, o leagility, que significa o uso conjunto da ME e da Manufatura Ágil. Essa nova visão é trabalhada por meio de um estudo de caso na cadeia de suprimentos de empresas de produtos eletrônicos. Mason-Jones et al. (2000) complementam esse trabalho, afirmando que a aplicação dos princípios enxutos, ágeis e deste novo conceito leagility dependem das necessidades específicas 
de cada cadeia de suprimentos. Essa argumentação é sustentada por estudos de caso nas indústrias de produtos mecânicos de precisão, tapeçaria e produtos eletrônicos, sendo que cada uma trabalha com uma abordagem. Yusuf \& Adeleye (2002) comparam as Manufaturas Enxuta e Ágil por meio de um survey em indústrias inglesas. Esses autores concluem que em um ambiente em mudança crescente a Manufatura Enxuta está ameaçada, enquanto a Manufatura Ágil surge como uma forte opção. Stratton \& Warburton (2003) trabalham com a integração de técnicas de fornecimento das Manufaturas Ágil e Enxuta na cadeia de suprimentos. Alguns autores relacionam a ME a indicadores de desempenho: Oliver et al. (1996) estudam a relação entre a Manufatura Enxuta e a performance das empresas, em um amplo estudo na indústria de componentes automotivos inglesa. Esses autores concluem que algumas práticas enxutas são necessárias, porém, não suficientes para a alta performance. De Toni \& Tonchia (1996) mostram que a busca por excelência e as mudanças organizacionais requeridas pela Manufatura Enxuta levam a empresa à gestão por processos, a qual influencia o sistema de medida de performance organizacional. Já Sánchez \& Pérez (2001) desenvolvem e testam um conjunto de indicadores de desempenho que avaliam as transformações de uma empresa rumo à Manufatura Enxuta. Esses autores também desenvolvem um estudo em empresas espanholas para mostrar quais desses indicadores são atualmente mais utilizados. Juliard (1997) demonstra em seu trabalho que os princípios da manufatura enxuta podem ser aplicados em grande variedade de situações e empresas. Porém, de acordo com Spear \& Bowen (1999), poucas têm alcançado o sucesso da Toyota. De acordo com esses autores, isso ocorre porque alguns princípios não estão explícitos no Sistema Toyota de Produção. Esses princípios são chamados por esses autores de DNA do Sistema Toyota de Produção. Finalmente, Bicheno et al. (2001) desenvolvem um algoritmo de programação da produção, que leva em consideração vários capacitadores enxutos como o kanban, a manutenção produtiva total e a redução nos tempos de set up.

\subsubsection{Trabalhos com foco em outras áreas da empresa e na cadeia de suprimentos (OA, CS)}

Nesta categoria, temos o trabalho de Pérez \& Sanchez (2000), que analisam os resultados de um survey realizado em 28 fornecedores de empresas automobilísticas da Espanha. Essa pesquisa teve por objetivo realizar algumas análises sobre a relação dos aspectos humanos e a relação clientefornecedor dentro da ME. Os autores concluíram que a rotatividade de tarefas e o trabalho em equipes relaciona-se positivamente com o treinamento e com o uso de componentes comuns. No relacionamento cliente-fornecedor, o trabalho concluiu que na prática há uma cooperação cliente- fornecedores para melhoria dos processos produtivos e de entrega. Porém, há pouca ou nenhuma cooperação em relação ao desenvolvimento dos componentes e projeto.

\subsubsection{Trabalhos com foco nas três áreas: chão de fábrica, outras áreas da empresa e cadeia de suprimentos (CF, AO, CS)}

Nesta categoria temos o trabalho de Panizzolo (1998), que mostra como o modelo de ME vem sendo implementado por meio de um estudo em 27 empresas. Os resultados dessa pesquisa mostram que para a implementação completa dos princípios enxutos o fator crítico é a gestão dos relacionamentos externos, integrando as diferentes empresas da cadeia de valor para garantir a excelência dos produtos e serviços. Já Lewis (2000), realizando três estudos de caso, avalia a relação entre $\mathrm{ME}$ e competitividade e questiona a ME como uma "panacéia para todos os males das empresas". Esse trabalho conclui que o desenvolvimento da ME não é único em todas as empresas, ou seja, cada empresa deve seguir sua própria trajetória enxuta (conclusão essa também mostrada no trabalho de Panizzolo (1998)). Além disso, os autores mostram que a ME leva a vantagens competitivas somente se a empresa souber investir os ganhos de produtividade que ela traz. Como alerta, os autores salientam a redução de flexibilidade que a ME pode trazer a longo prazo. Bamber \& Dale (2000) também questionam a ME como uma best practice em gestão de operações. Esses autores avaliam a aplicação dos métodos enxutos em uma tradicional empresa aeroespacial. E concluem que muitos dos métodos enxutos não se mostraram tão eficientes como na indústria automotiva em razão das características da demanda e da posição da empresa no mercado. Ainda nesta categoria temos o trabalho de Bruun \& Mefford (2004), que estudam as implicações da internet para a ME.

\subsection{Trabalhos teóricos}

\subsubsection{Trabalhos com foco no chão de fábrica (CF)}

Nesta categoria temos o estudo de Jakobs \& Meerkov (1993), que trabalham com a comparação da data prometida para clientes dentro de uma abordagem da manufatura em massa e da manufatura enxuta. Esses autores concluem que dentro da manufatura enxuta deve-se programar menor quantidade de trabalho do que na manufatura em massa para atingir os mesmos níveis de pontualidade. Ghinato (1995) apresenta um modelo que tem no just in time, na autonomação e no zero defeito os pilares do Sistema Toyota de Produção (STP). Além disso, o autor defende que o STP é mais do que somente o just in time. Dupernex \& Relph (1996) descrevem, no âmbito da ME, uma metodologia para redução do lead time por meio do aumento 
da utilização da capacidade e do emprego de lotes de fabricação menores. Edwards (1996) fornece um guia prático para a escolha de material que será empregado no chão de fábrica para uma implantação com sucesso da ME. Duggan (1998) também trabalha com ferramentas e com o projeto de uma fábrica enxuta. Dois autores fazem comparações entre a ME e outras metodologias: Harrison (1997) discute as diferenças e semelhanças entre a ME e a Manufatura Ágil, questionando a compatibilidade dessas duas teorias; Muffatto (1999) compara a ME com outro importante paradigma de gestão da produção, o Modelo Sueco. Já Hancock \& Zayko (1998) discutem os principais problemas passíveis de ocorrer na implantação da ME em empresas. Reynolds (1998) apresenta o projeto de um sistema de manufatura celular, dentro de um contexto de ME. Narayanaswamy (1997) apresenta um software para a análise e determinação de layouts em empresas. Esse software pode ser aplicado na manufatura, em depósitos, escritórios e em vários outros tipos de organizações de serviço. Ivezic et al. (1999) desenvolvem um sistema que suporta a transição de uma empresa tradicional para uma enxuta. Alvarez \& Antunes Jr. (2001) trabalham com o conceito de takt time dentro do STP.

\subsubsection{Trabalhos com foco em outras áreas da empresa (OA)}

Toomey (1994) trabalha com a relação entre ME e gestão de custos empresariais. $O$ autor conclui que, com a melhoria das operações de manufatura decorrente da implantação da $\mathrm{ME}$, a gestão de custos também deve melhorar para o que o autor chama de "custeio padrão enxuto". Maskell (2000) também trabalha com a relação entre um sistema financeiro e a ME, fazendo uma série de considerações a respeito de mudanças necessárias no sistema financeiro das empresas para que este se torne compatível com a ME. Já Womack \& Jones (1996) falam em seu trabalho da empresa enxuta, ou seja, da expansão do pensamento enxuto a todas as áreas e funções da empresa. Biazzo \& Panizzolo (2000) trabalham com a avaliação das mudanças, sob a perspectiva dos trabalhadores e das transformações que ocorrem na implantação da ME. Outro artigo que enfoca a relação dos recursos humanos na ME é o trabalho de Maccoby (1997), que faz uma série de comentários salientando a importância da força de trabalho para a ME. Knuf (2000) estuda a utilização do benchmarking na transformação de uma empresa tradicional em uma empresa enxuta.

\subsubsection{Trabalhos com foco na cadeia de suprimentos (CS)}

Dois trabalhos se encaixam neste grupo: o de Lamming (1996), que estuda a adequação da cadeia de suprimentos no paradigma enxuto, e o artigo de Steiner (1997), que trata de novos métodos para conseguir a cooperação entre produtores e fornecedores dentro de um ambiente da ME.

\subsubsection{Trabalhos com foco no chão de fábrica e em outras áreas da empresa (CF, OA)}

Neste grupo também temos somente um artigo, o de Karlsson \& Ahlströn (1996), que desenvolvem um modelo que pode ser usado para medir o progresso de uma empresa que está em processo de implantação da ME.

\subsubsection{Trabalhos com foco no chão de fábrica e na cadeia de suprimentos (CF, CS)}

Nesta categoria temos o trabalho de Hines \& Rich (1997), que apresenta um novo procedimento para realizar a análise da cadeia de valor, e o trabalho de Nave (2002), que mostra a base conceitual da ME, do seis sigma e da teoria das restrições, propondo um modelo para entender as semelhanças e diferenças entre cada uma dessas metodologias e também para escolher qual delas é mais adequada a uma empresa.

\subsubsection{Trabalhos com foco nas três áreas: chão de fábrica, outras áreas da empresa e cadeia de suprimentos (CF, OA, CS)}

Dentro desta categoria temos o trabalho de Warneche \& Hüser (1995), que identifica métodos enxutos para serem aplicados no que esses autores denominam de os quatro aspectos individuais da ME: desenvolvimento de produto, cadeia de suprimento, gestão do chão de fábrica e serviço pós-venda.

\section{Análise do tema Manufatura Enxuta na literatura e sugestões de futuros estudos}

Para melhor entendimento do que a literatura oferece atualmente sobre Manufatura Enxuta, bem como para a sugestão de futuros trabalhos na área, realizamos, nesta seção, uma análise geral da revisão bibliográfica utilizandose o sistema de classificação proposto. Esta análise se baseia em dois pontos fundamentais: i) estudo quantitativo das metodologias, abrangências, princípios e capacitadores utilizados nos trabalhos de produção enxuta e ii) estudo qualitativo dos principais assuntos e objetivos alcançados por esses trabalhos.

\subsection{Análise quantitativa das metodologias, abrangências, princípios e capacitadores}

Esta análise se baseia na classificação de trabalhos propostos e tem por objetivo verificar qual a freqüência da utilização das metodologias, abrangências, princípios e capacitadores dentro da literatura sobre Manufatura Enxuta. 
A primeira análise é referente às metodologias e abrangências dos trabalhos. Para isso, estruturamos a Tabela 4, que relaciona a metodologia utilizada no trabalho (duas categorias: prático ou teórico) com a abrangência do trabalho (sete categorias: desde um foco somente no chão de fábrica até outro nas três áreas, chão de fábrica, empresa e cadeia de suprimentos), mostrando o número de artigos para cada uma dessas classes combinadas.

A partir da Tabela 4 podemos extrair algumas informações interessantes a respeito das metodologias utilizadas e das abrangências dos trabalhos existentes atualmente na literatura a respeito da Manufatura Enxuta. Em relação à metodologia temos:

- 58 trabalhos (70,7\% do total) são do tipo prático, ou seja, utilizam metodologias de pesquisa do tipo survey, estudos de caso ou pesquisa-ação para abordar o tema Manufatura Enxuta. Somente 24 trabalhos (29,3\% do total) são teóricos, utilizando metodologias do tipo teóricoconceitual, como, por exemplo, discussões conceituais e revisões de literatura. A Figura 3 mostra estas considerações a respeito da metodologia empregada.

Já em relação à abrangência dos trabalhos, podemos tecer as seguintes considerações:
- Vemos que há grande diversidade de abrangências dentro dos trabalhos, tanto nos práticos quanto nos teóricos. Uma análise mais detalhada dessas abrangências mostra que, dentro dos artigos práticos, 44 $(75,9 \%)$ focalizam o chão de fábrica, $16(27,6 \%)$, outras áreas da empresa e $26(44,8 \%)$, a cadeia de suprimentos. Dentre os artigos teóricos, essas porcentagens são de $66,7 \%$ (16 artigos), 33,3\% (8 artigos) e $20,8 \%$ (5 artigos), respectivamente. No total (somando artigos práticos e teóricos), 60 artigos $(73,2 \%)$ analisam o chão de fábrica, $24(29,3 \%)$ estudam outras áreas da empresa e $31(37,8 \%)$ focalizam a cadeia de suprimentos. Uma observação importante a respeito dessas porcentagens é que elas não somam 100\%, pois há trabalhos que avaliam mais de uma área.

- Referente à ênfase em mais de uma área, temos, dentro dos trabalhos práticos, $34(58,6 \%)$ que enfatizam uma das três áreas $(\mathrm{CF}, \mathrm{AO}, \mathrm{CS})$, enquanto os outros 24 $(41,4 \%)$ enfatizam duas ou até mesmo três áreas. Em relação aos trabalhos teóricos, essas porcentagens são de $83,3 \%$ (20 trabalhos) e $16,7 \%$ (4 trabalhos), respectivamente. No total temos que 54 trabalhos $(65,9 \%)$ enfatizam somente uma área, enquanto os outros 28 $(34,1 \%)$ enfatizam duas ou até três áreas.

Tabela 4 - Número de trabalhos por metodologia e abrangência.

\begin{tabular}{lcccccccc}
\hline & $\begin{array}{c}\text { Foco } \\
\text { somente } \\
\text { no CF }\end{array}$ & $\begin{array}{c}\text { Foco } \\
\text { somente } \\
\text { em OA }\end{array}$ & $\begin{array}{c}\text { Foco } \\
\text { somente } \\
\text { na CS }\end{array}$ & $\begin{array}{c}\text { Foco no } \\
\text { CF e em } \\
\text { OA }\end{array}$ & $\begin{array}{c}\text { Foco no } \\
\text { CF e na } \\
\text { CS }\end{array}$ & $\begin{array}{c}\text { Foco em } \\
\text { OA e na } \\
\text { CS }\end{array}$ & $\begin{array}{c}\text { Foco no CF, } \\
\text { em OA e na } \\
\text { CS }\end{array}$ & Total \\
\hline $\begin{array}{l}\text { Número de } \\
\text { trabalhos } \\
\text { práticos }\end{array}$ & 21 & 4 & 9 & 7 & 12 & 1 & 4 & 58 \\
$\begin{array}{l}\text { Número de } \\
\text { trabalhos } \\
\text { teóricos }\end{array}$ & 12 & 6 & 2 & 1 & 2 & 0 & 1 & 24 \\
$\begin{array}{l}\text { Número de } \\
\text { trabalhos } \\
\text { total }\end{array}$ & 33 & 10 & 11 & 8 & 14 & 1 & 5 & 82 \\
\hline
\end{tabular}

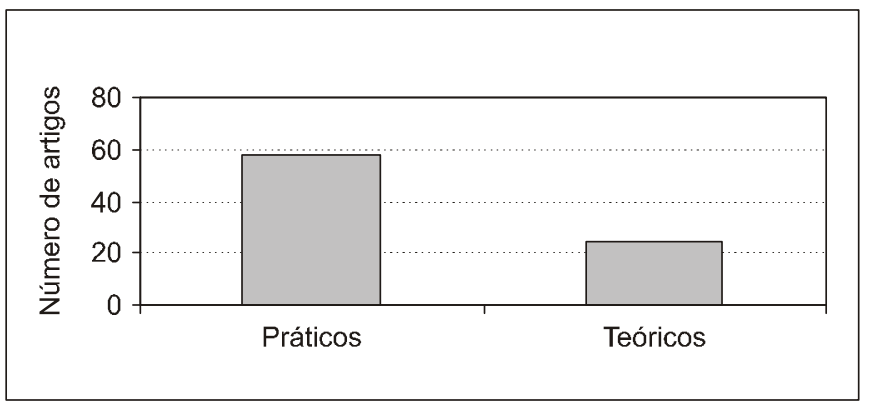

Figura 3 - Número de artigos de acordo com a metodologia empregada. 
Essas duas considerações a respeito das abrangências dos trabalhos sobre Manufatura Enxuta podem ser melhor visualizadas nas Figuras 4 e 5.

Ainda dentro de uma análise quantitativa da literatura sobre Manufatura Enxuta faremos agora considerações a respeito da terceira e quarta categorias de nosso sistema de classificação: os princípios e capacitadores da ME abordados nos trabalhos.

- Em relação aos princípios enxutos abordados nos trabalhos, elaboramos a Tabela 5, que mostra o número de trabalhos (teóricos, práticos e total) que aborda cada um dos princípios enxutos. Para facilitar, os princípios estão apresentados com os códigos (letras) do nosso sistema de classificação proposto. Nessa tabela notamos que o princípio C (Produção puxada/just in time) é o princípio mais estudado dentro dos trabalhos de Manufatura Enxuta, sendo abordado em 49 trabalhos (59,8\% do total de trabalhos). Outros princípios bastante tratados nos trabalhos são: trabalho em fluxo/simplificar fluxo (43 trabalhos ou 52,4\%); desenvolvimento e capacitação de recursos humanos (41 trabalhos ou 50\%); determinação do valor para o cliente, identificando a cadeia de valor e eliminando desperdícios (32 trabalhos ou 39\%) e autonomação/qualidade seis sigma (28 trabalhos ou $34,1 \%$ ). Dois princípios não estão tendo tanto destaque na literatura sobre Manufatura Enxuta: gerenciamento visual e limpeza, ordem e segurança, ambos tratados em somente 4 trabalhos (4,9\%). Ainda nessa tabela é interessante verificarmos a inexistência de trabalhos teóricos dentro da Manufatura Enxuta que tratem a fundo os princípios do gerenciamento visual e da limpeza, ordem e segurança dentro de um contexto da Manufatura Enxuta. A Figura 6 ilustra todas essas considerações.

- Em relação aos capacitadores, elaboramos a Tabela 6, que mostra a freqüência de utilização dos capacitadores enxutos nos trabalhos sobre Manufatura Enxuta. Também nessa tabela tratamos os capacitadores pelos seus códigos identificados em nosso sistema de classificação. Analisando a tabela vemos que três capacitadores enxutos são mais estudados dentro da literatura. São eles: o trabalho em equipes, o kanban e a tecnologia de grupo, estudados, respectivamente, em 41,5\%, 30,5\% e $28 \%$ dos trabalhos. Outros capacitadores bastante estudados (mais de 20\% dos artigos) são: o trabalho em fluxo contínuo/ redução do tamanho de lote (26,8\%); trabalhador multiespecializado/rodízio de funções e treinamento de pessoal (ambos tratados em 22\%); e melhoria na relação clientefornecedor/redução do número de fornecedores e kaizen (ambos tratados em 20,7\%). Já alguns capacitadores são tratados em um número extremamente reduzido de trabalhos. É o caso da utilização de medidas de performance enxutas (1,2\%); gráficos de controle visuais $(3,6 \%)$; entre outros capacitadores que podem ser vistos na Tabela 6 .

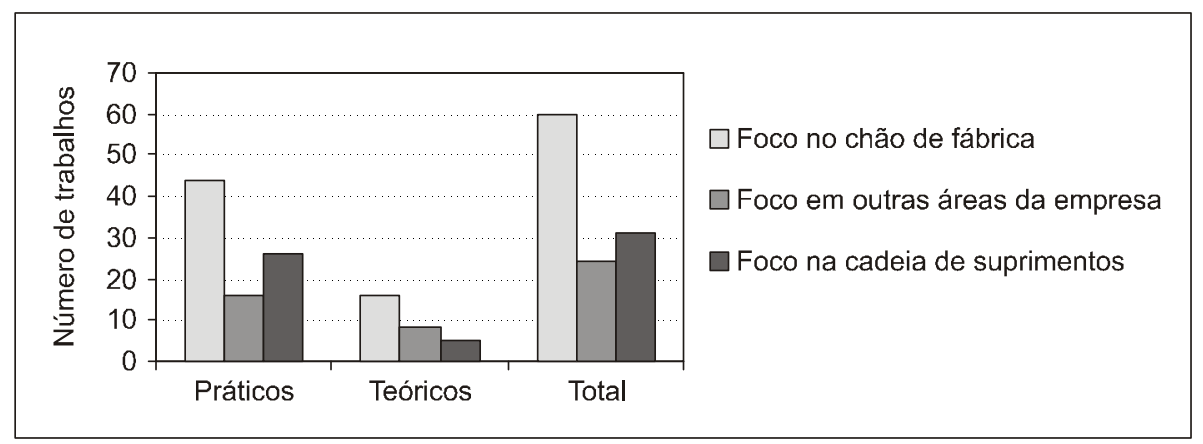

Figura 4 - Foco dos trabalhos sobre Manufatura Enxuta.

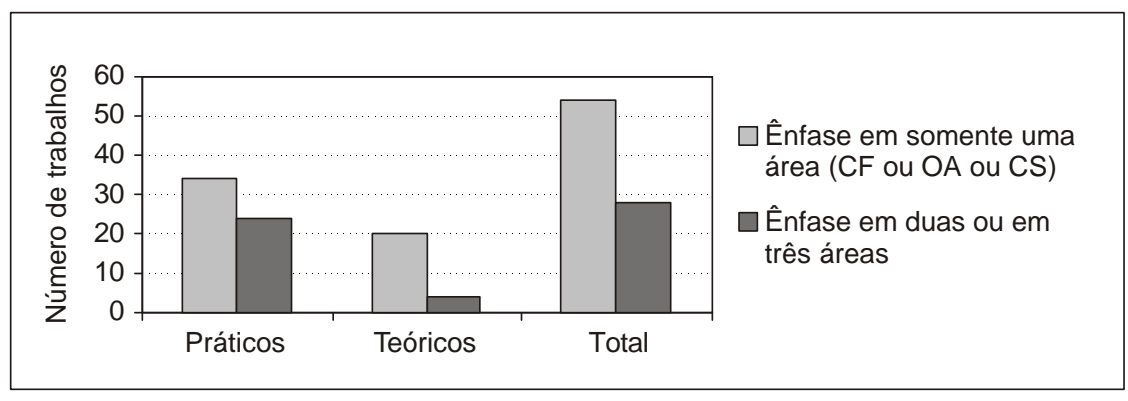

Figura 5 - Ênfase única ou múltipla nos trabalhos de Manufatura Enxuta. 


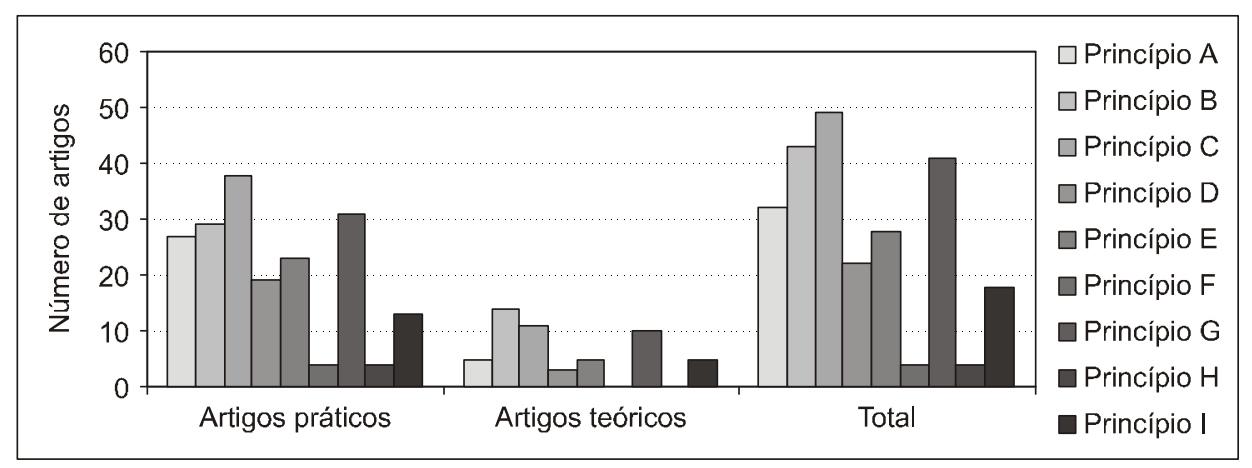

Figura 6 - Número de artigos que enfatizam cada um dos princípios enxutos (por metodologia e totais).

Tabela 5 - Número de artigos (divididos de acordo com a metodologia) relacionados a cada princípio enxuto.

\begin{tabular}{lccccccccc}
\hline & $\begin{array}{c}\text { Princípio } \\
\text { A }\end{array}$ & $\begin{array}{c}\text { Princípio } \\
\text { B }\end{array}$ & $\begin{array}{c}\text { Princípio } \\
\text { C }\end{array}$ & $\begin{array}{c}\text { Princípio } \\
\text { D }\end{array}$ & $\begin{array}{c}\text { Princípio } \\
\text { E }\end{array}$ & $\begin{array}{c}\text { Princípio } \\
\text { F }\end{array}$ & $\begin{array}{c}\text { Princípio } \\
\text { G }\end{array}$ & $\begin{array}{c}\text { Princípio } \\
\text { H }\end{array}$ & $\begin{array}{c}\text { Princípio } \\
\text { I }\end{array}$ \\
\hline $\begin{array}{l}\text { Artigos } \\
\text { práticos }\end{array}$ & 27 & 29 & 38 & 19 & 23 & 4 & 31 & 4 & 13 \\
$\begin{array}{l}\text { Artigos } \\
\text { teóricos }\end{array}$ & 5 & 14 & 11 & 3 & 5 & 0 & 10 & 0 & 5 \\
Total & 32 & 43 & 49 & 22 & 28 & 4 & 41 & 4 & 18 \\
\hline
\end{tabular}

Tabela 6 - Freqüência de abordagem dos capacitadores enxutos na literatura.

\begin{tabular}{ccccccccc}
\hline Capacitador & $\begin{array}{c}\text { Número } \\
\text { de } \\
\text { artigos }\end{array}$ & $\begin{array}{c}\text { Porcentagem } \\
\text { em relação } \\
\text { ao total de } \\
\text { trabalhos }\end{array}$ & Capacitador & $\begin{array}{c}\text { Número } \\
\text { de } \\
\text { artigos }\end{array}$ & $\begin{array}{c}\text { Porcentagem } \\
\text { em relação } \\
\text { ao total de } \\
\text { trabalhos }\end{array}$ & Capacitador & $\begin{array}{c}\text { Número } \\
\text { de } \\
\text { artigos }\end{array}$ & $\begin{array}{c}\text { Porcentagem } \\
\text { em relação } \\
\text { ao total de } \\
\text { trabalhos }\end{array}$ \\
\hline 1 & 6 & $7,3 \%$ & 9 & 16 & $19,5 \%$ & 17 & 14 & $17 \%$ \\
2 & 17 & $20,7 \%$ & 10 & 17 & $20,7 \%$ & 18 & 18 & $22 \%$ \\
3 & 13 & $15,9 \%$ & 11 & 11 & $13,4 \%$ & 19 & 18 & $22 \%$ \\
4 & 23 & $28 \%$ & 12 & 7 & $8,5 \%$ & 20 & 1 & $1,2 \%$ \\
5 & 22 & $26,8 \%$ & 13 & 5 & $6,1 \%$ & 21 & 3 & $3,6 \%$ \\
6 & 13 & $15,9 \%$ & 14 & 4 & $4,9 \%$ & 22 & 5 & $6,1 \%$ \\
7 & 13 & $15,9 \%$ & 15 & 13 & $15,9 \%$ & 23 & 5 & $6,1 \%$ \\
8 & 25 & $30,5 \%$ & 16 & 34 & $41,5 \%$ & & & \\
\hline
\end{tabular}

\subsection{Análise qualitativa dos principais assuntos e objetivos dos trabalhos}

Esta análise baseia-se na revisão bibliográfica estruturada apresentada na seção 4 e tem por principal objetivo servir de subsídio para maior entendimento da literatura existente atualmente sobre Manufatura Enxuta, assim como sugerir novas pesquisas na área. Os pontos mais importantes que destacamos são:
- Alguns autores trabalham com a ME dentro da indústria automobilística, onde nasceu esse conceito (Braiden \& Morrison, 1996; Mabry \& Morrison, 1996; Kochan, 1998; entre outros). Já outros autores trabalham com a ME dentro de outros tipos de indústrias: aeroespacial (James-Moore \& Gibbons, 1997; Lang \& Hugge, 1995); naval (Storch \& Lim, 1999); elevadores (Korosen \& Buhanist, 1994); entre outras. Apesar da expansão da ME para outras indústrias, Bamber \& Dale (2000) 
salientam que muitos métodos enxutos não são tão eficazes em todos os tipos de empresas. Apesar disso, acreditamos que há amplo espaço na literatura para estudos da ME em outras indústrias.

- Muitos autores focalizam especificamente aspectos da implantação da ME. Dentro deste contexto parece haver duas vertentes de pensamento. A primeira, representada por Ahlstrom (2000), sugere uma seqüência de implantação ideal para a ME; a segunda vertente, representada por autores como Panizzolo (1998), Allen (2000) e Lewis (2000), defende que a implantação enxuta é diferente de empresa para empresa. Essa questão pode ser melhor estudada no futuro.

- Vários autores apresentam diferenças e semelhanças entre ME e outros paradigmas, como Manufatura Ágil e Manufatura Adaptável. Exemplos destes trabalhos são Katayama \& Bennett (1996, 1999), Naylor et al. (1999), entre outros. Esse tema está longe de ser esgotado.

- Atualmente, a simulação vem sendo utilizada por alguns autores (Detty \& Yingling, 2000) para quantificar e justificar a implantação de técnicas enxutas nas empresas. Estudos de simulação podem ser aprofundados e ampliados, incluindo comparações da ME com outros paradigmas estratégicos de gestão da manufatura.

- Dentro dos trabalhos que estudam a ME em outras áreas das empresas, vemos que a literatura abrange basicamente a ME em duas áreas: sistemas financeiros/contábeis/custos enxutos (Toomey, 1994; Karlsson \& Ahlstrom, 1995; 1996; Maskweel, 2000) e sistemas de recursos humanos (Niepce \& Molleman, 1996; Boyer, 1996; Maccoby, 1997). A princípio, outras áreas poderão ser estudadas.

- Vários autores focalizam a ME dentro de contextos específicos de certos países, como, por exemplo, China (Dong, 1995), Japão (Katayama \& Bennett, 1996, 1999), Austrália (Sohal, 1996), Brasil (Arkader, 2001), Inglaterra (Dennis \& Robinson, 2000), Índia (Gulyani, 2001) e Finlândia (Kosonen \& Buhanist, 1994). Comparações entre os estudos em diferentes países podem ser realizados.

- E para finalizar, muitos autores tratam da questão ME e da melhoria dos padrões competitivos (Lewis, 2000; Bamber \& Dale, 2000; Oliver et al., 1996). Esses autores mostram que a Manufatura Enxuta nãoé solução para todos os males e deve ser implantada de acordo com os objetivos estratégicos da empresa. Em particular, já estamos trabalhando no aprofundamento dessa questão em pesquisa.

\section{Conclusões}

O presente trabalho, em primeiro lugar, teve por objetivo realizar ampla revisão bibliográfica sobre a Manufatura Enxuta. A partir dessa revisão pode-se propor um sistema de classificação para a ME com base em quatro parâmetros: metodologia, abrangência, princípios e capacitadores. Utilizando esse sistema foram classificados todos os artigos encontrados na literatura. Esse procedimento serviu de base para a estruturação de toda a revisão bibliográfica e para uma ampla análise (quanti e qualitativa) do tema ME na literatura. As principais contribuições deste trabalho são: maior conhecimento do tema e sugestões de novas pesquisas, ambas resultantes da análise realizada na seção anterior. Um resumo desta análise é mostrada a seguir:

- Sobre a metodologia de pesquisa utilizada em trabalhos sobre ME vimos que a maioria $(70,7 \%)$ utiliza metodologia prática (estudos de caso, surveys ou pesquisa-ação).

- Em relação à abrangência dos trabalhos, notamos que a maioria focaliza o chão de fábrica $(73,2 \%)$, enquanto as outras áreas e a cadeia de suprimentos tem frequiências menores (29,3\% e 37,8\%). Riis \& Johansen (2001) citam a existência de duas abordagens na literatura a respeito das diferenças entre as Manufaturas Enxuta e Ágil: uma delas considera os dois conceitos totalmente ortogonais (defendida por autores como Gunasekaran et al., 2001; Sharife \& Pawar, 2001) e direcionados a objetivos diferentes, e outra defende que ambas são conceitos complementares (defendido por autores como Sharp et al., 1999; Naylor et al., 1999), sendo que a Manufatura Enxuta é direcionada para a busca de eficiência no chão de fábrica e a Manufatura Ágil preocupa-se com a empresa. Nossa pesquisa mostrou que, apesar de o objetivo da manufatura ser o chão de fábrica, esta tem preocupações mais amplas referentes também à empresa e a toda a cadeia de valor. Acreditamos que entender a Manufatura Enxuta somente como eficiente no chão de fábrica é restringir demais seu espectro de atuação. Ainda em relação à abrangência, constatamos que os autores que avaliam a ME tendem a focalizar somente uma das três áreas em seus trabalhos (65,9\%), enquanto os outros $34,1 \%$ focam duas ou três áreas em seus trabalhos.

- Em relação aos princípios enxutos, vimos que os mais abordados pelos trabalhos são: produção puxada/just in time, trabalho em fluxo/simplificação do fluxo e desenvolvimento e capacitação de recursos humanos. Os menos estudados são gerenciamento visual e ordem, limpeza e segurança.

- A respeito dos capacitadores enxutos tratados nos trabalhos, temos que o trabalho em equipe, o kanban e a tecnologia de grupo são os capacitadores mais abordados pela literatura, enquanto a utilização de medidas de performance enxutas e de gráficos de controle visuais são os capacitadores menos trabalhados na literatura. 
- As constatações encontradas apontam para diversas pesquisas futuras. Assim, mostrou-se que, apesar de a ME estar sendo estudada em outras indústrias que não necessariamente a automobilística, diversas outras indústrias podem ser estudadas nas práticas enxutas. Também foram apresentadas duas vertentes na literatura que têm diferentes opiniões sobre a implantação enxuta: ela deve seguir uma ordem de implementação ideal ou em cada empresa esta implementação deve ser diferente? Esta questão pode ser estudada mais a fundo no futuro. Foram apresentados diversos trabalhos que diferenciam a ME e outros paradigmas estratégicos de gestão da manufatura; em Godinho Filho (2004) aprofundamos esta questão. Verificou-se que a simulação pode ser utilizada para as empresas justificarem e quantificarem os ganhos com a ME (muitos trabalhos nesta área podem ser aprofundados e ampliados). Verificou-se ainda que há significativo número de referências que tratam os aspectos financeiros/contábeis/custos e de recursos humanos no contexto da ME, sendo que outras áreas podem ser focadas. Mostrou-se que a ME pode ser estudada a partir de diferentes realidades nacionais e que poderão surgir trabalhos que comparem os diferentes enfoques em diferentes países e confirmou-se a idéia de que a ME não é solução para todos os males; sua aplicação vai depender dos objetivos estratégicos da empresa em questão e já estamos trabalhando no aprofundamento dessa questão de pesquisa.

\section{Referências Bibliográficas}

ALVAREZ, R. R.; ANTUNES Jr., J. A. V. Takt time: contexto e contextualização dentro do Sistema Toyota de Produção. Revista Gestão \& Produção, v. 8, n. 1, p. 01-18, abr. 2001.

AHLSTRÖM, P. Sequences in the implementation of lean production. European Management Journal, v. 16, n. 3, p. 327-334, 1998.

AHLSTRÖM, P.; KARLSSON, C. Change processes towards lean production: the role of the management accounting system. International Journal of Operations \& Production Management, v. 16, n. 11, p. 42-56, 1996.

ALLEN, J. H. Make lean manufacturing work for you. Manufacturing Engineering, v. 6, p. 54-64, 2000.

ARBÓS, L. C. Design of a rapid response and high efficiency service by lean production principles - methodology and evaluation of variability of performance. International Journal of Production Economics, v. 80, p. 169-183, 2002.

ARKADER, R. The perspective of suppliers on lean supply in a developing country context. Integrated Manufacturing Systems, v. 12, n. 2, p. 87-93, 2001.

BAMBER, L.; DALE, G. Lean production: a study of application in a traditional manufacturing environment. Production Planning \& Control, v. 11, n. 3, p. 291-298, 2000.

BARKER, R. C. The design of lean manufacturing systems using time-based analysis. International Journal of Operations \& Production Management, v. 14, n. 14, p. 86-96, 1994.

BERTO, R. M. V. S.; NAKANO, D. N. Metodologia da pesquisa e a engenharia de produção. In: ENCONTRO NACIONAL DE ENGENHARIA DE PRODUÇÃO (ENEGEP), 18., e INTERNATIONAL CONGRESS OF INDUSTRIAL ENGINEERING (ICIE), 4., 1998. Niterói, RJ: UFF/ABEPRO, out. 1998. CD-ROM.

BERTO, R. M. V. S.; NAKANO, D. N. A produção científica nos anais do encontro nacional de engenharia de produção: um levantamento dos métodos e tipos de pesquisa. In: ENCONTRO NACIONAL DE ENGENHARIA DE PRODUÇÃO (ENEGEP), 19., e INTERNATIONAL CONGRESS OF INDUSTRIAL ENGINEERING (ICIE), 5., 1999. Rio de Janeiro, RJ: UFRJ/ABEPRO, nov. 1999. CD-ROM.
BERTO, R. M. V. S.; NAKANO, D. N. A produção científica nos anais do encontro nacional de engenharia de produção: um levantamento dos métodos e tipos de pesquisa. Produção, v. 9, n. 2, p. 65-75, jul. 2000.

BIAZZO, S.; PANIZZOLO, R. The assessment of work organization in lean production: the relevance of the worke's perspective. Integrated Manufacturing Systems, v. 11, n. 1, p. 6-15, 2000.

BICHENO, J.; HOLWEG, M.; NIESSMANN, J. Constraint batch sizing in a lean environment. International Journal of Production Economics, v. 73, n. 1, p. 41-49, 2001.

BILLESBACH, T. J. Appying lean production principles to a process facility. Production and Inventory Management Journal, Third Quarter, p. 40-44, 1994.

BOYER, K. K. An assessment of managerial commitment to lean production. International Journal of Operations \& Production Management, v. 16, n. 9, p. 48-59, 1996.

BRAIDEN, B. W.; MORRISSON, K. R. Lean manufacturing optimization of automotive motor compartment system. 19th International Conference on Computers and Industrial Engineering, v. 31, n. 1/2, p. 99-102, 1996.

BROWN, S. New evidence on quality in manufacturing plants: a challenge to lean production. Production and Inventory Management Journal, first quarter, p. 24-29, 1998.

BRUUN, P.; MEFFORD, R. N. Lean Production and the Internet. International Journal of Production Economics, Article in Press, 2004.

BURCHER, P.; DUPERNEX, S.; RELPH, G. The road to lean repetitive batch manufacturing-modeling planning system performance. International Journal of Operations \& Production Management, v. 16, n. 2, p. 210-220, 1996.

DE TONI, A.; TONCHIA, S. Lean organization, management by process and performance measurement. International Journal of Operations \& Production Management, v. 16, n. 2, p. 221-236, 1996. 
DENNIS, S.; KING, B.; HIND, M.; ROBINSON, S. Applications of business process simulation and lean techniques in British Telecommunications PLC. Winter Simulation Conference Proceedings, v. 2, p. 2015-2021, 2000.

DETTY, R. B.; YINGLING, J. C. Quantifyng benefits of conversion to lean manufacturing with discrete event simulation: a case study. International Journal of Production Research, v. 38, n. 2, p. 429-445, 2000.

DONG, W. Y. Lean production and industrial engineering. 17th International Conference on Computers and Industrial Engineering, v. 29, n. 1-4, p. 233-237, 1995.

DUGGAN, K. J. Facilities design for lean manufacturing. IIE Solutions, Dec., p. 30-34, 1998.

EDWARDS, D. K. Practical guidelines for lean manufacturing equipment. Production and Inventory Management Journal, second quarter, p. 51-55, 1996.

ERRIDGE, A.; MURRAY, J. G. The application of lean supply in local government: the Belfast experiments. European Journal of Purchasing \& Supply Management, v. 4, p. $207-$ 221, 1998.

FERNANDES, F. C. F. A pesquisa em Gestão da Produção: evolução e tendências. In: ENCONTRO NACIONAL DE ENGENHARIA DE PRODUÇÃO (ENEGEP), 19., e INTERNATIONAL CONGRESS OF INDUSTRIAL ENGINEERING (ICIE), 5., Rio de Janeiro, RJ: UFRJ/ ABEPRO, nov. 1999. CD-ROM.

FILIPPINI, R. Operations management research: some reflections on evolution, models and empirical studies in OM. International Journal of Operations and Production Management, v. 17, n. 7, p. 655-670, 1997.

FORZA, C. Work organization in lean production and traditional plants. What are the differences? International Journal of Operations \& Production Management, v. 16, n. 2, p. 42-62, 1996.

GHINATO, P. Sistema Toyota de Produção - mais do que simplesmente Just in Time. Revista Produção, v. 5, n. 2, p. 169-190, 1995.

GODINHO FILHO, M. Paradigmas estratégicos de gestão da manufatura - configuração, relações com o planejamento e controle da produção e estudo exploratório na indústria de calçados. 2004. Tese (Doutorado) Universidade Federal de São Carlos, São Carlos.

GODINHO FILHO, M.; FERNANDES, F. C. F. Um sistema para classificar e codificar os trabalhos relacionados com o Controle da Produção e o Controle da Qualidade. Revista Gestão \& Produção, v. 10, n. 1, abr. 2003.

GOOD, I. J. Categorization of classification. In: Mathematics and Computer Science in Medicine and Biology. London: HMSO, 1965. p. 115-128.

GULYANI, S. Effects of poor transportation on lean production and industrial clustering: evidence from the indian auto industry. World Development, v. 29, n. 7, p. 1157-1177, 2001.
GUNASEKARAN, A.; MCGAUGHEY, R.; WOLSTENCROFT, V. Agile manufacturing - concepts and framework. In: GUNASEKARAN, A. (Ed.). Agile manufacturing: the 21st century competitive strategy. Elsevier, 2001.

HAMPSON, I. Lean production and the Toyota Production System - or, the case of the forgotten production concepts. Economic and Industrial Democracy, v. 20, n. 3, p. 369391, 1999.

HANCOCK, W. M.; ZAYKO, M. J. Lean production implementation problems. IIE Solutions, p. 38-42, jun. 1998.

HARRISSON, A. From leanness to agility. Manufacturing Engineer, p. 257-260, dec. 1997.

HENDERSON, B. A.; LARCO, J. L. Lean transformation. Richmond, Virgínia: The Oaklea Press, 2000.

HINES, P.; RICH, N. The seven value stream mapping tools. International Journal of Operations \& Production Management, v. 17, n. 1, p. 46-64, 1997.

IVEZIV, N.; POTOK, T. E.; POUCHARD, L. Multiagent framework for Lean Manufacturing. IEEE - Internet Computing, v. 3, n. 5, p. 58-59, 1999.

JACOBS, D.; MEERKOV, S. M. Due-time performance in Lean and Mass manufacturing environments. Proceedings of the 32nd Conference on Decision and Control, San Antonio, Texas, dec. 1993, p. 3259-3263.

JAMES-MOORE, S. M.; GIBBONS, A. Is lean manufacture universally relevant? An investigate methodology. International Journal of Operations \& Production Management, v. 17, n. 9, p. 899-911, 1997.

JOHNSTON, R. B. Making manufacturing practices tacit: a case study of computer-aided production management and lean production. Journal of the Operational Research Society, v. 46, p. 1174-1183, 1995.

JULIARD, P. Lean Manufacturing: a process of all seasons. Proceedings of the Electrical Electronics Insulation Conference, IEEE, Piscataway, NJ, USA, 1997. p. 849-851.

KARLSSON, C.; AHLSTRÖM, P. Assessing change towards lean production. International Journal of Operations \& Production Management, v. 16, n. 2, p. 24-41, 1996.

KARLSSON, C.; AHLSTRÖM, P. Change processes towards lean production: the role of the remuneration system. International Journal of Operations \& Production Management, v. 15, n. 11, p. 80-99, 1995.

KATAYAMA, H.; BENNETT, D. Agility, adaptability and leanness: a comparison of concepts and a study of practice. International Journal of Production Economics, v. 60-61, p. 43-51, 1999.

KATAYAMA, H.; BENNETT, D. Lean production in a changing competitive world: a Japanese perspective. International Journal of Operations \& Production Management, v. 16, n. 2, p. 8-23, 1996.

KNUF, J. Benchmarking the Lean Enterprise: Organizational learning at work. Journal of Management in Engineering, v. 16, n. 4, p. 58-71, Jul./Aug. 2000. 
KOCHAN, T. A.; LANSBURY, R. D. Lean production and changing employment relations in the international auto industry. Economic and Industrial Democracy, v. 18, p. 597620, 1997.

KOCHAN, T. A. Automotive industry looks for lean production. Assembly Automation, v. 18, n. 2, p. 132-137, 1998.

KOJIMA, S.; KAPLINSKY, R. The use if a lean production index in explaining the transition to global competitiveness the auto components sector in South Africa. Technovation. Article in Press, 2003.

KOSONEN, K.; BUHANIST, P. Customer focused lean production development. International Journal of Production Economics, v. 41, p. 211-216, 1995.

LAMMING, R. Squaring lean supply with supply chain management. International Journal of Operations \& Production Management, v. 16, n. 2, p. 183-196, 1996.

LANG, J. D.; HUGGE, P. B. Lean manufacturing. Aerospace America, p. 28-33, May 1995.

LEWIS, M. A. Lean Production and sustainable competitive advantage. International Journal of Operations \& Production Management, v. 20, n. 8, p. 959-978, 2000.

LEWIS, M. A. Lean production and sustainable competitive advantage. International Journal of Operations \& Production Management, v. 20, n. 8, p. 959-978, 2000.

MABRY, B. G.; MORRISON, K. R. Transformation to lean manufacturing by an automotive component supplier. 19th International Conference on Computers and Industrial Engineering, v. 31, n. 1/2, p. 95-98, 1996.

MACCOBY, M. Is there a best way to build a car? Harvard Business Review, p. 161-167, Nov./Dec. 1997.

MACDUFFIE, J. P.; HELPER, S. Creating Lean Suppliers diffusing lean production through the supply chain. California Management Review, v. 39, n. 4, Summer 1997.

MASKELL, B. H. Lean accounting for lean manufacturers. Manufacturing Engineering, n. 12, p. 46-53, 2000.

MASON-JONES, R.; NAYLOR, B.; TOWILL, D. R. Lean, agile or leagile? Matching your supply chain to the marketplace. International Journal of Production Research, v. 38, n. 17, p. 4061-4070, 2000.

MONDEN, Y. Sistema Toyota de Produção. São Paulo: IMAM, 1984.

MORAS, R. G.; JALALI, M. R.; DUDEK, R. A. A categorized survey of the JIT literature. Production Planning and Control, v. 2, n. 4, p. 322-334, 1991.

MUFFATTO, M. Evolution of production paradigms: the Toyota and Volvo cases. Integrated Manufacturing Systems, v. 10, n. 1, p. 15-25, 1999.

NARAYANASWAMY, R. Strategic layout planning for lean manufacturing - a LayOPTTM tutorial. Winter Simulation Conference Proceedings, p. 640-644, 1997.

NAVE, D. How to compare six sigma, lean and the theory of constraints. Quality Progress, p. 73-78, Mar. 2002.
NAYLOR, J. B.; NAIM, M. M.; BERRY, D. Leagility: integrating the lean and agile manufacturing paradigms in the total supply chain. International Journal of Production Economics, v. 62, p. 107-118, 1999.

NELLORE, R.; CHANARON, J. J.; SÖDREQUIST, K. E. Lean supply and price-based global sourcing - the interconnection. European Journal of Purchasing \& Supply Management, v. 7, p. 101-110, 2001.

NIEPCE, W.; MOLLEMAN, E. Characteristics of work organization in lean production and sociotechnical systems. International Journal of Operations \& Production Management, v. 16, n. 2, p. 77-90, 1996.

OHNO, T. O sistema Toyota de produção - além da produção em larga escala. Porto Alegre: Artes Médicas, 1997.

OLIVER, N.; DELBRIDGE, R.; LOWE, J. Lean Production Practices: International Comparisons in the Auto Components Industry. British Journal of Management, v. 7, special issue, p. S29-S44, 1996.

PANIZZOLO, R. Applying the lessons learned from 27 lean manufacturers. The relevance of relationships management. International Journal of Production Economics, v. 55, p. 223-240, 1998.

PÉREZ, M. P.; SÁNCHEZ, A. M. Lean production and supplier relations: a survey of practices in the Aragonese automotive industry. Technovation, 20, p. 665-676, 2000.

PRINCE, J.; KAY, J. M. Combining lean and agile characteristics: creation of virtual groups by enhanced production flow analysis. International Journal of Production Economics, v. 85, p. 305-318, 2003.

REYNOLDS, K. T. Cellular manufacturing and the concept of total quality. 23rd International Conference on Computers and Industrial Engineering, v. 35, n. 1-2, p. 89-92, 1998.

RIIS, J. O.; JOHANSEN, J. A strategic approach to develop agile manufacturing. In: GUNASEKARAN, A. (ed.). Agile Manufacturing: the 21st Century Competitive Strategy. Elsevier, 2001.

ROBINSON, A. Modern approaches to manufacturing improvement - the Shingo System. Cambridge: Productivity Press, 1990.

SÁNCHEZ, A. M.; PÉREZ, M. P. Lean indicators and manufacturing strategies. International Journal of Operations \& Production Management, v. 21, n. 11, p. 1433-1451, 2001.

SCHURING, R. W. Operational autonomy explains the value of group work in both lean and reflective production. International Journal of Operations \& Production Management, v. 16, n. 2, p. 171-182, 1996.

SHAH, R.; WARD, P. T. Lean manufacturing: context, practice bundles, and performance. Journal of Operations Management, v. 335, p. 1-21, 2002.

SHAHMANESH, N. The lean machine. Manufacturing Review, p. 56-59, Jan. 1999. 
SHARIFI, S.; PAWAR, K. S. Product development strategies for agility. In: GUNASEKARAN, A. (Ed.). Agile manufacturing: the 21st Century Competitive Strategy, Elsevier, 2001.

SHARP, J. M.; IRANI, Z.; DESAI, S. Working towards agile manufacturing in the UK industry. International Journal of Production Economics, v. 62, p. 155-169, 1999.

SHINGO, S. A revolution in manufacturing: the SMED System. Cambridge: Productivity Press, 1985.

SHINGO, S. O sistema Toyota de produção - do ponto de vista de Engenharia de Produção. Porto Alegre: Artes Médicas, 1996a.

SHINGO, S. Sistemas de produção com estoque zero - o Sistema Shingo para melhorias contínuas. Porto Alegre: Artes Médicas, 1996 b.

SOHAL, A. S. Developing a lean production organization: an Australian case study. International Journal of Operations \& Production Management, v. 16, n. 2, p. 91-102, 1996.

SORIANO-MEIER, H.; FORRESTER, P. L. A model for evaluating the degree of leanness of manufacturing firms. Integrated Manufacturing Systems, v. 13, n. 2, p. 104-109, 2002.

SPEAR, S.; BOWEN, H. K. Decoding the DNA of the Toyota Production System. Harvard Business Review, Sep./Oct. 1999.

STEINER, E. L. Importance of the supplier in the lean manufacturing process. Proceedings of the Electrical Electronics Insulation Conference, IEEE. Piscataway, NJ, USA, 1997. p. 853-856.

STORCH, R. L.; LIM, S. Improving flow to achieve lean manufacturing in shipbuilding. Production Planning \& Control, v. 10, n. 2, p. 127-137, 1999.

STRATTON, R.; WARBURTON, R. D. H. The strategic integration of agile and lean supply. International Journal of Production Economics, v. 85, p. 183-198, 2003.
SULLIVAN, W. G.; MCDONALD, T. N.; VAN AKEN, E. M. Equipment replacement decisions and lean manufacturing. Robotics and Computer Integrated Manufacturing, v. 18, p. 255-265, 2002.

TOOMEY, J. W. Adjusting management systems to lean manufacturing environments. Production and Inventory Management Journal, third quarter, p. 82-85, 1994.

VINCENTI, A., Lean machine, Automotive Engineer, p. 5859, Jan. 2002.

WARDT, J. P.; Brief: lean drilling - introducing the application of automotive lean manufacturing techniques to well construction. Journal of Petroleum Technology, v. 47, n. 2, p. 113-114, 1995.

WARNECKE, H. J.; HÜSER, M. Lean production. International Journal of Production Economics, v. 41, p. 3743, 1995.

WHITE, R. E.; PRYBUTOK, V. The relationship between JIT practices and type of production system. Omega - The International Journal of Management Science, v. 29, p. 113124, 2001.

WOMACK, J. P.; JONES, D. T.; ROOS, D. A máquina que mudou o mundo. 14. ed. Rio de Janeiro: Campus, 1992.

WOMACK, J. P.; JONES, D. T. From lean production to the lean enterprise. IEEE Engineering Management Review, p. 38-46, 1996.

WOMACK, J. P.; JONES, D. T. A mentalidade enxuta nas empresas. 5. ed. Rio de Janeiro: Campus, 1998.

YUSUF, Y. Y.; ADELEYE, E. O. A comparative study of lean and agile manufacturing with a related survey of practices in the UK. International Journal of Production Research, v. 40, n. 17, p. 4545-4562, 2002.

ZAYCO, M. J.; BROUGHMAN, D. J.; HANCOCK, W. M. Lean manufacturing yields world-class improvements for small manufacturer. IIE Solutions, p. 36-40, Apr. 1997.

\title{
LEAN MANUFACTURING: A LITERATURE REVIEW WHICH CLASSIFIES AND ANALYSES PAPERS INDICATING NEW RESEARCH AREAS
}

\begin{abstract}
This work reviews the literature on Lean Manufacturing (LM). Until now, there was no complete literature review regarding this subject in the Operations Management literature. Based on this literature review it is proposed a LM classification system based on 4 main characteristics: methodology, comprehension, principles and enablers. The system is used to classify and to organize the papers. After that a general analyses of LM is performed. The LM analyses is based on 2 main points: $i$ ) a quantitative study of the methodology, comprehension, principles and enablers within LM papers; ii) a qualitative study regarding the main subjects and goals accomplished by the papers. The main contributions of this work are to contribute for mental clarification, communication and discovering new fields for research on $L M$.
\end{abstract}

Key words: Lean Manufacturing, review. 